Portland State University

PDXScholar

Winter 2-16-2015

\title{
The Right to Dream: Assessing the Spatiality of a Homeless Rest Site in Portland, Oregon
}

Stephen Przybylinski

Portland State University

Follow this and additional works at: https://pdxscholar.library.pdx.edu/open_access_etds

Part of the Geography Commons

Let us know how access to this document benefits you.

\section{Recommended Citation}

Przybylinski, Stephen, "The Right to Dream: Assessing the Spatiality of a Homeless Rest Site in Portland, Oregon" (2015). Dissertations and Theses. Paper 2199.

https://doi.org/10.15760/etd.2196

This Thesis is brought to you for free and open access. It has been accepted for inclusion in Dissertations and Theses by an authorized administrator of PDXScholar. Please contact us if we can make this document more accessible: pdxscholar@pdx.edu. 
The Right to Dream:

Assessing the Spatiality of a Homeless Rest Site in Portland, Oregon

by

Stephen Przybylinski

A thesis submitted in partial fulfillment of the requirements for the degree of

\author{
Master of Arts \\ in \\ Geography
}

Thesis Committee:

Martha Works, Chair

Hunter Shobe

David Banis

\title{
Portland State University
}

2015 
C 2014 Stephen Przybylinski 


\begin{abstract}
The continued increase in homelessness in Portland, Oregon is in part a result of the systemic restructuring of the welfare state as well as a shift in local governance purviews. Primarily this has eradicated the affordable housing stock in the city which is compounded by the limited availability of emergency shelter spaces. These and other financial constraints have left a depleted service support system to cover a rising homelessness problem. In response to this, contemporary social movements have been focusing attention on economically marginalized groups such as the homeless, calling for rights to access resources in cities such as housing. This approach critiques the neoliberal policies that have bolstered entrepreneurial approaches to urban growth. Neoliberal policies result in a failure to maintain financial support for the well-being of the homeless and connected support services. This research examines one alternative to the traditional approach to sheltering the homeless. It focuses on a self-organized homeless tent city in downtown Portland, Right 2 Dream Too, which has become a critical resource in homeless emergency service provisioning. The rest site's success as an emergency service is primarily predicated on its geographic proximity to a nexus of social services in the Old Town neighborhood. Drawing on ethnographic work and archival data, I analyze the multiple spatialities of this self-managed site to better understand homeless individuals' experience with this place and other related spaces, as a means to understand its value as an emergency service for the homeless in Portland, and other cities with similar constraints. I argue this perspective is essential for mitigating homelessness in Portland and informing the decision-making surrounding its relocation.
\end{abstract}




\section{Dedication}

This thesis is dedicated to Dr. Thomas Harvey, who began this project with me and has yet to see the end of it. As my original advisor, Dr. Harvey was equally fascinated in the content lying herein and would be surprised to see where it landed. I would be equally happy to see his response to it as a final product. This is in memory of him. 


\section{Acknowledgements}

This project deserves much recognition for many people have helped make it happen. I must first acknowledge the support of my family through my schooling. It is they who encourage me to continue on the uncertain, yet continually stimulating and satisfying, path that I have found. And to Maggie, for understanding my dedication to this project and my schooling more broadly. She has patiently supported me throughout.

Dr. Martha Works has been incredibly supportive with not only her instruction on writing and organizing this thesis, but holistically supportive and understanding of my goals for this work and in the future. Dr. Hunter Shobe has been incredibly supportive of this research as well and has always taken the time to offer feedback for the many ideas that perhaps are not always fully thought-through when I barge in. I take comfort in the ability to talk so freely with him about everything. The same goes for David Banis. He has been equally supportive of my myriad interests within this project and others not entirely related. He has extended his time again and again to help me think things through. 


\section{Table of Contents}

Abstract

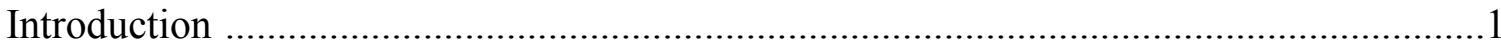

Chapter I: The Rise of Urban Influence in the Global Economy ..................................10

Restructuring Urban Governance ..................................................................13

Changes in Urban Economic Development: Market-Driven Approach ...............17

The Decline of Affordable Housing ..............................................................20

Chapter II: Impacts on U.S. Cities: The Case of Portland …....................................22

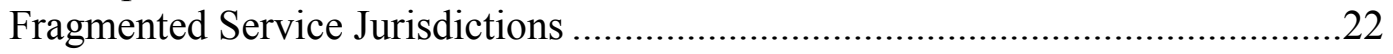

Affordable Housing Shortages in Portland ..................................................25

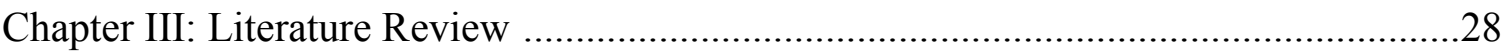

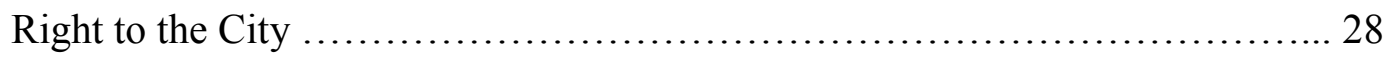

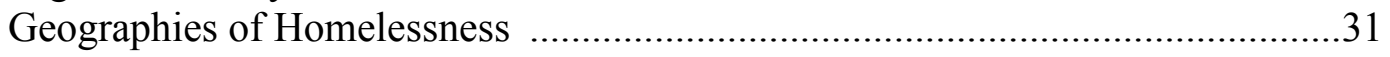

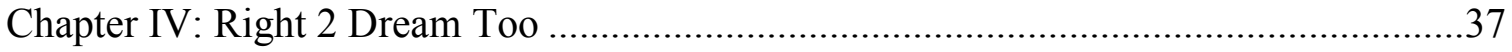

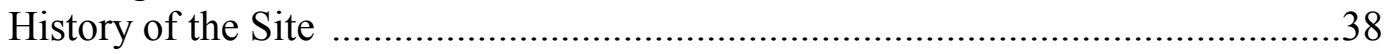

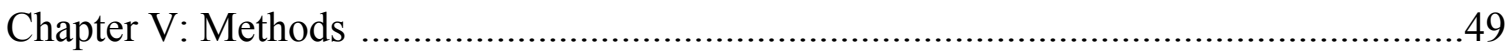

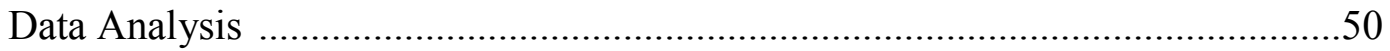

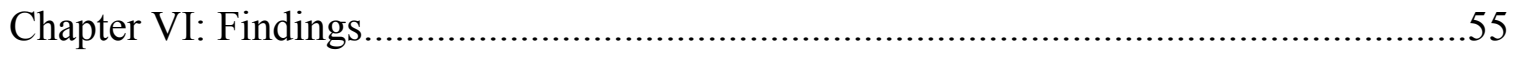

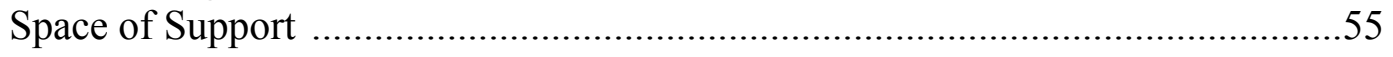

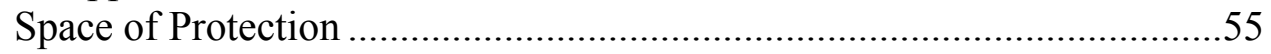

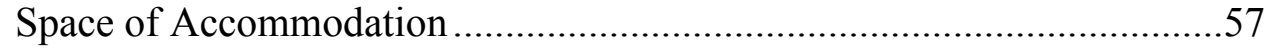

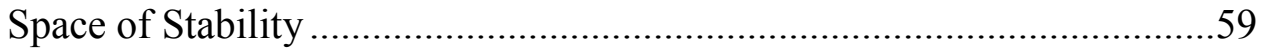

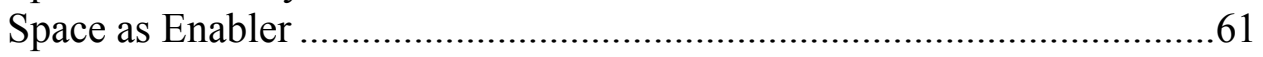

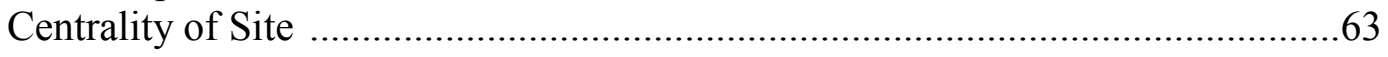

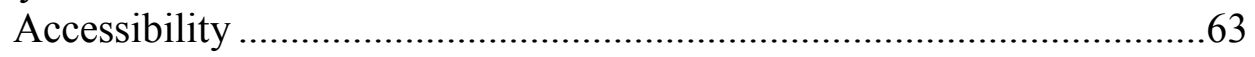




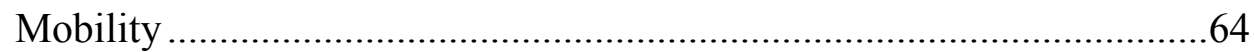

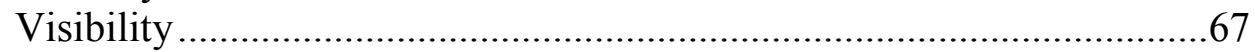

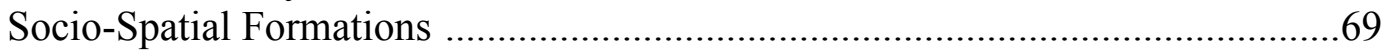

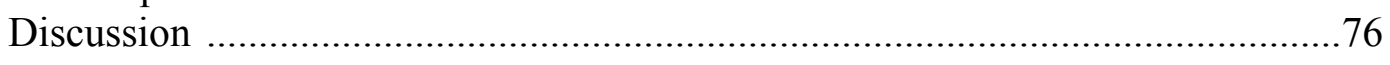

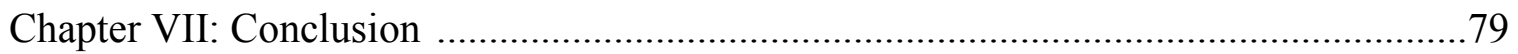

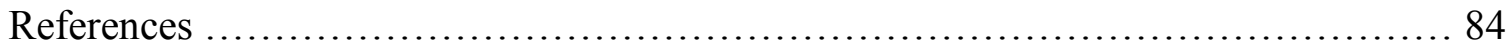

Appendices

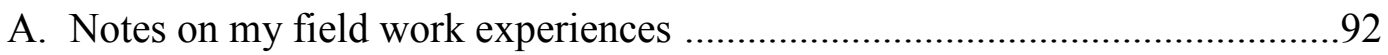

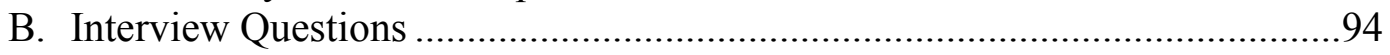

C. Code Percentages and Frequency ..............................................................95

D. Human Subjects Review Approval .......................................................96 


\section{List of Tables}

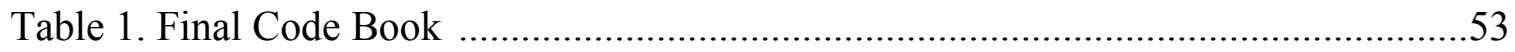

Table 2. Social Services Used by R2DT Sleepers ....................................................66 


\section{List of Figures}

Figure 1. HUD budget authority and homeless assistance from 1976-2009 ..................21

Figure 2. Location of R2DT in downtown Portland, Oregon ........................................39

Figure 3. R2DT's doored-fence looking west on Burnside Street..................................40

Figure 4. A typical sleeping space for overnighters. ...............................................62

Figure 5. Social services used by those staying at R2DT …....................................67

Figure 6. Member's section with individual tents ................................................

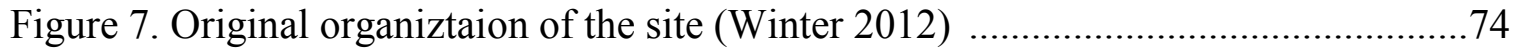

Figure 8. Current organization of the rest site (October 2014) ....................................75 


$\begin{array}{ll}\text { BNC } & \text { Burnside Neighborhood Committee } \\ \text { CDBG } & \text { Community Development Block Grants } \\ \text { COC } & \text { Continuums of Care } \\ \text { HUD } & \text { Housing and Urban Development } \\ \text { IGA } & \text { Intergovernmental Agreement } \\ \text { MFI } & \text { Median Family Income } \\ \text { OAR } & \text { Oregon Administrative Rule } \\ \text { OWS } & \text { Occupy Wall Street } \\ \text { PDC } & \text { Portland Development Commission } \\ \text { R2DT } & \text { Right 2 Dream Too } \\ \text { SRO } & \text { Single Room Occupancy } \\ \text { SSBG } & \text { Social Service Block Grants } \\ \text { TNC } & \text { Transnational Corporations } \\ \text { TPI } & \text { Transition Projects Inc. }\end{array}$




\section{Introduction}

Portland, Oregon is often heralded as a 'progressive' or 'liberal' place. These terms are particularly applied to the city with regard to its style of permissive politics and “intelligent urban planning" (Miller 2014). It is a city that is touted as one of the most sustainable and livable cities in the U.S., featuring multiple amenities that particularly are attractive to younger individuals and families (Revkin 2008, Flanagin 2014). Mirroring a contemporary "back-to-the-city," reurbanization movement, where people are moving back into central cities at greater numbers than to suburban or exurban areas, Portland is experiencing high growth rates compared with other major metropolitan areas in the United States (Cox 2014). From 2000 to 2010, the population increased more than 53,000 residents; a roughly ten percent increase. Estimates from 2013 show that it has gained 26,000 residents since the 2010 decennial census (U.S. Census Bureau 2014). While these aspects of growth have been a popular focus for Portland, long-standing social problems continue to affect the city, contradicting the notion of almost utopian-like place.

One systemic issue in Portland over the last three decades is the pervasive presence of homelessness. A Portland Housing Bureau point-in-time count from 2013 estimated that on any given night, 15,917 in Portland and Multnomah County people are considered homeless in the broadest definition ${ }^{1}$ (Smock 2013). Specifically, the

\footnotetext{
${ }^{1}$ This report defines four iterations of homelessness. The first, unsheltered, is the most visible population, and includes "people sleeping outside, in vehicles, abandoned buildings, or other places not intended for human habitation". The second, those defined as literally homeless, refers to the unsheltered population as well as "the homeless sleeping in emergency shelters or vouchered into motels". The third is HUD's definition of homeless, which includes the literally homeless as well as "those sleeping in transitional housing for the homeless". The fourth, and broadest definition of homelessness, is defined as all of the above categories as well as "individuals and families who are sharing the housing of other persons due to the loss of housing or economic hardship" (Smock 2013, 6).
} 
unsheltered homeless population saw an increase of ten percent, or 177 people, since the last count in 2011. The report cites unemployment as a primary reason for the increase, noting that the economic recession of late has made it extremely difficult to find and maintain adequate employment.

One familiar with downtown Portland will probably recall seeing men and women sleeping tucked into doorways of businesses and sidewalks, along the side of buildings and overpasses, and in city parks. One primary issue for Portland in this regard is that there simply is not enough space to shelter the homeless. Although there is no official count of emergency shelter spaces, a Portland homeless rights advocate believes there are about 700-800 beds available for the homeless on any given night (T. Shannon, Right to Dream board member, March 2013). This number of beds is not enough to meet the needs of the estimated 1,900 homeless that are unsheltered on any given night in Portland and Multnomah County (Smock 2013). With shelters at capacity there is little recourse for the homeless, often forcing individuals to find unsafe spaces to sleep.

Making this issue more complex is the continued threat of funding reductions for urban social services. Specifically, the City of Portland Housing Bureau has faced cuts to many services for the homeless including: the elimination or reduction of shelter beds, recuperative care services, short-term rent assistance, mental health outreach, and stable housing initiatives (Bayer 2013, 5). Other funding decreases such as supplemental nutrition assistance are also falling from recent spikes from the Federal Recovery Act (CBP 2014). These hardships force homeless individuals, social service agencies, and social rights advocacy groups to be increasingly adaptive in fiscally austere times. 
Particularly for the unsheltered homeless, this necessary flexibility is often at odds with strict urban, spatially-controlling policies. The unsheltered homeless are generally the more visible portion of the homeless population as they lack consistent shelter. As the unsheltered homeless are more commonly living on the street, this population is particularly affected by such punitive spatial policies. For instance, although Portland no longer enforces a sit-lie ordinance banning the obstruction of any public sidewalk, the Chronic Offender Pilot Project is a new initiative that affords police officers control over public spaces wherever they might see an individual unnecessarily occupying any given space. This new initiative, also known as 'Prosper Portland' is intended to "wake up" homeless people obstructing doorways or other public spaces as to ensure the homeless do not impede public access to those spaces (Bernstein 2014, Vanderhart 2014). These legislative dictates, combined with public animosity, necessarily makes living on the street that much more difficult for the unsheltered homeless.

Unfortunately Portland's problems are not unique but, rather, reflect challenges for homeless in urban areas all over North America. A Housing and Urban Development (HUD) point-in-time count from January of 2014 found roughly 578,000 homeless in the United States, more than 177,000 of whom were unsheltered ${ }^{2}$ (U.S. HUD 2014). For the unsheltered population, this is a decrease of almost ten percent from 2013 to 2014. Additionally, from 2007 to 2014, the decrease of unsheltered homeless has been more than thirty-one percent. State-level aggregates also reflect that homelessness is

\footnotetext{
${ }^{2}$ Using the Housing and Urban Development definition, the unsheltered homeless are people who stay in places not meant for human habitation, such as streets, abandoned buildings, vehicles, or parks. In contrast, sheltered homeless are "individuals staying in emergency shelters, transitional housing programs, or safe havens" (HUD 2014, 2).
} 
decreasing. In the state of Oregon, the unsheltered population decreased by more than eleven percent from 2013 to 2014.

These trends seemingly indicate that unsheltered homelessness is declining across the country. Yet, national and state-level aggregates of homeless counts do not reflect localized changes in homeless populations. In the urban or regional context for instance, positive or negative changes in unsheltered populations are not accounted for from HUD's national data set. This is problematic, in that national homeless counts obscure the issues surrounding particularly urban homelessness.

The distinction between the national unsheltered homeless population and urban, or local, unsheltered populations is important to make, since homelessness in the U.S. is predominantly urban. Recent HUD estimates indicate that 70 percent of the sheltered homeless population in the U.S. is found in principal cities, or the largest city in a given metropolitan statistical area (U.S HUD 2012). HUD does not provide estimates for the percentage of urban homeless that is unsheltered, however. Therefore, to analyze how unsheltered populations fluctuate, specifically at the urban-level, it is necessary to look at local or regional-level data provided by individual cities or their Continuums of Care ${ }^{3}$.

When looking at major U.S. cities' homeless counts, it is clear that unsheltered homeless populations are increasing. Homelessness is prominent on the West Coast, where climates are more temperate and amenable to outdoor habitation. Los Angeles for

\footnotetext{
${ }^{3}$ Continuums of Care (CoCs) are "local planning bodies responsible for coordinating the full range of homelessness services in a geographic area, which may cover a city, county, metropolitan area, or an entire state"(U.S. HUD 2014, 2). CoCs often send in individual cities point-in-time homeless counts to aggregate the national-level statistics that HUD publishes.
} 
example has long been a major hub of street homelessness, with its highly publicized Skid Row district. A 2013 point-in-time count found over 58,000 homeless individuals in Los Angeles County ${ }^{4}$, with an unsheltered population of 40,864 (LHASA 2013). This is an increase of sixteen percent from the last count in 2011. San Francisco also has a long history of visible homelessness. Its 2013 point-in-time count found an eight percent increase from 2011 of its unsheltered population, increasing from 3,106 to 3,401 (SFHC 2013). Seattle, a city of similar size and climate to Portland, also showed an increase in their unsheltered homeless population. From 2012 to 2013, its unsheltered population rose two percent, from 2,594 to 2,657 people. Portland is just one of many cities experiencing an increase in unsheltered homeless populations. National statistics are telling of general trends, but at the urban and regional scale, large metropolitan areas are still seeing increases in unsheltered homeless populations.

An acute geographic issue surrounding homelessness, then, is that high concentrations of unsheltered homeless are aggregated within urban areas. This is not to say that urban homelessness constitutes all homelessness. Indeed, rural poverty research has expanded the breadth of research on homelessness. For instance, research has cast light on the 'visibility' of the geographies of rural homelessness (Cloke 2000, Cloke et al. 2001). However, because a majority of the homeless population in the U.S. is found in urban areas, understanding the "urbanity" of homelessness is critical in attempting to

\footnotetext{
${ }^{4}$ Los Angeles County is comprised of four Homeless Continua of Care (systems to address homelessness). The Los Angeles Continuum represents about $90 \%$ of the total of Los Angeles County. Other CoCs in the County include the cities of Long Beach, Glendale and Pasadena. "Hidden Homeless" are estimates included into the counts (LHASA 2013).
} 
mitigate homelessness. This means that a deeper socio-economic understanding of urbanization processes is required to uncover the production and reproduction of impoverished and marginalized spaces found in today's major cities.

The focus of this thesis is, then, on the relationship between urban economic processes and geographies of homelessness. It questions how economic globalization has restructured urban economic processes as well as inspired shifts in urban governance approaches. I examine how has this affected urban governments' capacity for care services for the low-income and destitute. How are the homeless, particularly in Portland, adapting to these barriers to stability? And is there a particular spatiality to the geographies of homelessness in Portland? This research advances new means of thinking about Portland's ability to manage increasing homelessness.

The first chapter examines how restructuring of the global economy over the last 70 years has affected urban governments and the welfare state. Specifically I am interested in the structural aspects behind the increase in homelessness in urban areas. I draw on different urban theories to trace the changing role of urban governance with regard to the increased participation of cities within the global economy as well as the restructuring of the federal welfare state.

For many urban governments, the diminishing role of federal welfare spending has invoked a competitive, entrepreneurialist approach to economic development. This has simultaneously promoted urban growth through direct investment in land use development while attempting simply to maintain necessary community services, such as, 
emergency shelters, subsidized or affordable housing programs, food assistance programs, and mental and physical health care. Urban governments' tendencies to develop cities oriented toward the global economy have resulted in the subsequent decline of this type of welfare spending and security.

The third chapter looks at how these global, national, and regional processes have affected Portland. Affordable housing has become extremely polarized, where lowincome renters are not able to find a small amount of housing, while higher income renters have more opportunities to find rental units. These socio-economic disparities between housing availability are a significant barrier for the homeless to obtaining stable housing. Regional-level issues stemming from bureaucracies add complexity to the homeless' search for stability as well. Municipal jurisdictions for urban service provisioning in the Portland area have been rescaled, making the distribution of these services more difficult to implement. This has had a large impact particularly on housing assistance, which has forced homeless service provisioning to become increasingly fragmented and adaptive.

The fourth chapter draws on the narratives surrounding the "right to the city" concept to help situate the changing social organization of urban spaces in response to the urban economic processes of the last half century. The "right to the city ideas" help to realize the potential of organizing cities to be more inclusive of residents' needs and desires. Particularly it is encompassing of those who are economically or socially marginalized from public and private urban spaces. It is a useful conceptual tool for thinking through alternatives to the means by which cities manage homelessness. The 
second section of this chapter situates the existing research on the geographies of homelessness. This literature is particularly robust and my overview spans three decades of various approaches. Illuminating the many perspectives of this research reinforces the significance of my own contribution to the geographic research on urban homelessness.

The final chapters include my own research on urban homelessness. Specifically, my case study focuses on the self-organized rest site Right 2 Dream Too (R2DT), a tent city located in downtown Portland. It draws on ethnographic work I conducted with individuals staying at R2DT to better understand their sense of place and of the many socio-spatial interactions that produce the rest site.

Previous research on tent cities has focused on both West Coast (National Coalition for the Homeless 2010) and East Coast U.S. rest sites (Hunter et al. 2014). This research, while important, diverges from my approach in that its purpose is to catalog the myriad rest sites in these regions. This research does not consider rest sites that are located in prominent downtown urban spaces nor has it focused on the experiences of the individuals residing within these semi-permanent or permanent structures. R2DT's relative permanence within downtown Portland affords a more detailed assessment of a tent city's operations in the context of the greater urbanization processes.

This research, therefore, contributes to the geographic literature on homelessness through a few different means. First, it seeks to identify homeless individuals' relationship with the social and spatial aspects of the rest site. This perspective helps in identifying the many socio-spatial barriers to obtaining stability the homeless are often 
faced with. Additionally, the study recognizes the greater structural influences that contemporary urban development can have on homeless individuals' ability to find housing stability as well as simply navigate urban space in their daily lives. Therefore, it considers the R2DT rest site as a response to these barriers affecting homeless individuals in Portland and other urban areas, and presents the rest site as an innovative alternative to managing homelessness in U.S. cities. Furthermore, it seeks to understand the lived experience of these individuals and how they are contingent upon the geography of social service providers.

Portland is struggling to deal with some of the negative consequences of growth: rents are becoming higher on average, fewer affordable housing units are available to match the population growth of the city, and fewer resources are available to manage poverty in general. And while the development of every city is unique, there has been a general pattern across the U.S. of disinvestment in urban areas. The increase in homelessness in major cities across the U.S. is a direct result of the disinvestment in social welfare programs. The financial circumstances of urban areas over the last several decades are also tied to changes in global and national economic priorities. This series of changes is discussed in the next chapter. 


\section{Chapter I - The Rise of Urban Influence in the Global Economy}

To begin to understand structural changes leading to urban homelessness it is useful to trace the function of cities within processes of economic globalization. The shifting organization of economies often reflects the socio-economic disparities of populations. These disparities are most marked in urban areas, particularly with regard to the visibility of abject poverty.

Cities are often the hubs of economic and financial activity within nation-states making them increasingly influential in an ever globalizing world. The role of cities in the global economy has been widely researched over the last three decades. They are places central to the reproduction and constitution of multi-scale capitalist economic policies (Brenner et al 2002, Peck et al. 2002). They are also places where city governments play a prominent role in the reshaping of everyday life through different socio-economic policies (Keil 2002). This research has led to relatively distinct situations of the urban within greater processes of economic globalization.

Perhaps the most foundational approach to studying the urban in relation to the global economy has been through world, or "global cities" analysis. It is through this lens that global cities are thought of as prime centers for capital accumulation as well as anchors for financialization industries that are the foundation of contemporary market economies. The catalysts for world city research, Friedmann and Wolff, suggested in 1982 that the "emerging global system of economic relations assumes its material form in particular, typically urban, localities that are enmeshed with the global system in a variety of ways. The specific mode of integration with this system gives rise to an urban 
hierarchy of influence and control" (p. 310). Their emphasis was on how economically powerful particular cities were becoming around the world.

Although this recognition was influential in understanding cities' role in the production of the global economy, Brenner (2006) argues that much of the world cities research of this era was based off the notion that furthering globalization processes would necessarily erode the territoriality of the national state. This zero-sum position of world cities analysts assumes that what the global economy 'gains,' the national state will 'lose'. For Friedmann and Wolff, then, global cities were not seen as connected at the global scale as much as they were seen as sites of economic production for the nationstate.

More recently however, this scalar dichotomy of the global/national connection to urban areas has been contested. For instance, Sassen (2000) argues that the effects of globalization on nation-states are not furthering denationalization of state territorial jurisdiction, but rather of the institutional configuration of state sovereignty. This supports the notion that the global economy is still embedded in the geographies of the nation-state, necessarily involving the state within the processes of sustaining a global economy. Most importantly, Sassen notes that the global economy "needs to be produced, reproduced, serviced and financed... [and] global cities are strategic sites for the production of these specialized functions" $(2000,373)$. As central sites for the concentration of financial services within national states, cities and their greater urban regions are inherently subject to restructuring processes of their national states reacting to larger changes in the global economy. 
While more cities are increasingly becoming integrated with the global economy, it is important to analyze how cities' governments are affected by global processes of economic restructuring. For, cities are not solely entities which concentrate global corporate financial power. They are simultaneously managers of the social well-being of the constituents within the city as well. Urban governments thus are responsible for the holistic development of the city: development that equally benefits the disadvantaged and impoverished. Cities' participation within the global economy is also predicated on the social reproduction of its inhabitants. This necessarily "places" society within global processes.

The socio-political organization of cities is then of importance for the production of the city. Economic organizers of urban and regional governments are significant actors who influence the social and political processes of urban areas. In this sense, urban and regional governments are embedded in the global economy as well. As Brenner (2006) notes "because urban regions occupy the contradictory interface between the world economy and territorial state, they are embedded within a multiplicity of politicaleconomic processes organized upon a range of superimposed geographical scales" ( $\mathrm{p}$. 265-66). Brenner's recognition of the unique positionality of urban regions in relation with the global economy is more succinctly understood by Swyngedouw's (2004) conceptualization of global-localism. He uses the term "glocalization" to highlight the implications of the economic restructuring of the nation-state at both the global and urban or regional scales. As a result of restructuring, power is diffused through these institutional rearrangements from one scale to another. Interscalar connectivity between 
city-regions and the national and global scale has reconstituted and rescaled governance of urban regions.

As a result of increasing global connectivity, cities are realizing new responsibilities and roles that were formerly not enacted by urban governments. Kiel (2003) suggests that the nation-state is not "withering away," as much as former national powers are being reincarnated in many forms at various socio-spatial levels. Thus, his claim that "globalization makes states" (p. 278) with regard to political entities supports the notion that local states are also an outcome of globalization processes. Local states are not political-economic alternatives to "traditional" nation-states, however; as administrative authority of cities and urban regions are not entirely sovereign, nor are they simply byproducts of a withered nation-state. Instead, as Kiel argues, "the local state has perforations at its interface with the dynamized, global, city civil society perforations that provide openings for resistance and alternatives to hegemonic globalization" $(2003,279)$. Focusing on the rescaling of sovereignty to the sub-national scale, specifically for urban governments, helps to identify how global processes have affected particular urban political economies, and in turn how urban political economies affect global economic processes. One process that has particularly affected the capacities of urban governments to address socio-economic inequalities is seen through governance restructuring.

\section{Restructuring Urban Governance}

Beginning after World War II, until the early 1970s, Keynesian welfarist economic policies influenced government decision-making. These policies supported 
strong union power, significant state control over the economy and capital, and a large welfare state (Purcell 2008). It was during this period especially that social service expenditures increased along with an increased recognition of the number of the needy (Knox et al. 2005). Also significant during this epoch was that a majority of social spending was instituted at the national scale. As Brenner et al. argue (2003) there was "a socially constructed correspondence between the national economy as the primary object of economic management, the national state as the primary political scale on which economic management was conducted and social welfare was delivered, and the treatment of political subjects as national citizens" (p. 4). While the national state was relatively prolific in social spending in these decades, urban governments were generally more focused on infrastructural developments such as urban renewal programs. Perhaps due to this focus, maintaining healthy budgets for social programs was not a primary concern for urban governments because the federal budget filled that supporting role for municipalities.

In the 1970s however, economic problems were pervasive in cities all over North America, if not throughout the world. A few major economic events inspired the financial crisis that would fundamentally reorganize cities spatially and economically. For example, in 1971 the Bretton Woods system abandoned the dollars convertibility to gold, and in 1973 abandoned fixed exchange rates (Wolch et al. 1993). The oil crisis of 1973 is another event that is often cited as the impetus for global financial crisis. Harvey (2012) argues that a third event, a global property crash earlier in that year, was also a major aspect in the economic downturn. A final action that was economically significant was 
exemplified through the New York City debt bail-out in 1975. This decision was exemplary in that private finance protection was honored instead of the City's public expenditures, especially with worker's pensions as the focus of this decision. This set the precedent that protection of capital was privileged over 'big government' and the wellbeing of its citizens (Harvey 2005). These economic events were partially responsible for initiating the processes of industrial reorganizing, and other structural changes in urban areas, that signaled the transition to a post-industrial or advanced capitalist urban economy (Pacione 2009).

The transition to a post-industrial economy was not instantaneous, but a gradual process. Fordist-era production that formerly helped maintain employment and economic growth in cities post-World War, was beginning as early as the late 1960s to be offshored to countries with lenient labor standards. Transnational corporations (TNCs) primarily headquartered in highly developed countries and predominantly in large urban centers were major propagators of this shift. It was largely in the 1970s, that TNCs began securing larger-scale connections with the global economy by redirecting investments and establishing production in undeveloped countries. This new international division of labor stemmed from the decentralization of industrial production from the developed countries to low-cost production areas in undeveloped countries, particularly to export production zones (McMichael 2012). The shift to more flexible modes of production, endemic of post-Fordist regimes, had deleterious effects for North American cities.

For cities, deindustrialization meant the disappearance of jobs. The unemployment and underemployment that ensued led to lower incomes, increasing the 
rate of poverty. Outmigration from urban cores was escalated by these measures, but had already begun after World War II with suburbanization. As a consequence of inner city outmigration, depopulating urban areas had decreasing tax bases which had supplemented municipal spending on urban services. Urban governments' economic situations were deteriorating and because of this, were failing to provide and maintain important social and physical infrastructures for their populations.

Demarcating a shift from a Keynesian welfarist approach, Harvey (1989) cited a new 'entrepreneurialism' influencing urban governments in the 1970s and 1980s. This was a period of increasing deindustrialization, unemployment, and fiscal austerity for cities. What commonly distinguishes the 'entrepreneurial' period from the former 'managerial' phase of urban governance, however, was the "diminished role of the city government as provider of welfare services and collective consumption" (Hall et al. 2012). Harvey $(1989,5)$ suggests that it was also the "rising tide of neconservatism and much stronger appeal... to market rationality and privatization" that indicates why urban governments took similar paths toward entrepreneurialism. For Harvey, the new entrepreneurialism was predicated on a "private-public partnership focusing on investment and economic development with speculative construction of place rather than amelioration of conditions within a particular territory as its immediate...political and economic goal" (p. 8). This transition was not holistic for all cities nor did a perfect linear-temporal process unfold. Certainly cities experienced these transitions differently. Indeed this is a major reason that the current social geographies of cities within the U.S. are so uneven. 
While the decline in federal funds burdened urban governments with respect to providing social infrastructure, it simultaneously instituted more autonomy for cities as political-economic actors. The entrepreneurial governance approach is focused on attracting capital to develop the city economically and thus expand the tax base. Although an entrepreneurial approach to governing cities does not a priori eliminate the ability of cities to administer social welfarist programs, major cities equally do not have the ability to bolster fledgling social programs on their own.

A return to the Keynesian approach of federally-funded social support does not seem likely. Instead, cities continue to be promoted as sites of direct investment for private development. This continues to have pernicious effects on the impoverished and indigent within cities. It is this population that is generally not seeing the economic prosperity of urban growth as socio-spatial inequalities continue to increase. Further compounding urban governments' capacity to adequately address these growing inequalities is the limited support of social welfare services.

\section{Changes in Urban Economic Development: Market-Driven Approach}

Connected to the diminishing role of urban governments in providing expansive social programs was a dismantling of the U.S. welfare state. In 1978, the federal government promoted national disengagement with urban affairs taking the stance that government was incapable of eliminating poverty or creating a flourishing economy (Knox 2005). One target of this was support services for the neediest. At the beginning of the Reagan administration in the early 1980s the federal government began rolling back welfare programs, arguing that market forces were more effective than the public sector 
in reducing poverty (von Mahs 2001). These declines in social spending had an enormous impact on many urban programs, but spending for programs assisting the impoverished and the homeless were particularly affected.

Throughout the 1980s for example, public housing programs were discontinued, mental health facilities were deinstitutionalized, and there were reductions in social programs that provided cash assistance, putting extra pressure on local entities to increase eligibility standards to receive aid or eliminate them completely (Knox 2005, von Mahs 2001, Wolch et al. 1993). The austerity trends of the welfare state lessened some in the mid-1990s, but would continue to impact cities with even less subtlety leading into the housing crisis of the mid-2000s ${ }^{5}$.

The U.S. welfare state was not only dismantled. It also experienced an internal transformation (Wolch et al. 1993). This included the devolution of responsibility and allocation of resources for the poor from a national level to a state or local level. Eventually, beyond decentralizing social welfare responsibilities, non-governmental agencies took over these care activities. Prevalent today are non-profit and religiousbased care facilities that make up a significant part of social services, particularly for the homeless.

\footnotetext{
${ }^{5}$ It should be noted that the privileging of capital over social service expenditures did not completely occlude federal spending in cities. For instance, extra funding for cities became available from the federal government beginning in 1974 through Community Development Block Grants (CDBGs) and Social Service Block Grants (SSBGs). These grants supported the implementation of much needed community sustenance in emptied-out inner city areas. Funds for these programs peaked in the 1980s, however. And while CDBGs are issued for various purposes in cities today, they remain highly contested due to misallocations and spells of corruption (Malanga 2012).
} 
The 1980s and 1990s saw a continued rise of market fundamentalist practices, or neoliberalism, as a political-economic model for growth. Neoliberal ideology is grounded in the assumption that governments are not the appropriate entity to create economic growth, or provide social welfare. Instead, this ideology contends that "private companies, private individuals, and, most importantly, unhindered markets are best able to generate economic growth and social welfare" (Bockman 2013, 14). Therefore, neoliberals advocate for shrinking government as well as for the further deregulation of the market. This entails that ownership and control over economic enterprise should be privatized and that social services be defunded (Purcell 2013). What is more, beyond attempting to steer government out of economic oversight, neoliberal ideology remains flexible in influencing more than economic policy, by disciplining those in noncompliance with these policies. Peck and Tickell (2002) term these two phases of neoliberalism as "roll-back" then "roll-out," indicating the movement of neoliberals from initially stripping back the state from the market, and then actively building a sociopolitical narrative of privatization and individualism.

Von Mahs (2001) argues that neoliberal policies that have much influence over political and economic decisions today require governments to curtail spending in order to maintain global competitiveness. Thus, the "public functions of the nation-state (i.e., the welfare institutions) have to be decentralized, privatized, recommodified, and devolved to the local/urban level" (Von Mahs, 457). Jessop (2002) similarly argues that economies are being restructured at the cost of welfare spending as to continue the production of the global economy. As a result, federal defunding of social programs that 
aim to mitigate poverty has been continual for decades in cities. The resultant cost for operating social programs is left to the responsibility of cities and other organizations that assist the needy. The effects of this can be seen in increasing rates of poverty and homelessness in cities across North America. Perhaps the most significant aspect of welfare restructuring for cities was the destruction of affordable housing.

\section{The Decline of Affordable Housing}

In the 1980s, the cutting back of federal spending on housing assistance was a major cause for the homeless crisis that began around this time. Specifically it was the decrease in funding for construction of new subsidized housing and the decrease in quantity of affordable units that made it difficult for low-income people to find affordable housing. Funding for the construction of new affordable units was at its peak in the six year span from 1976-1982, where the Department of Housing and Urban Development (HUD) built over one million new subsidized housing units (U.S. Gov Means and Ways 2014). Subsequently, in the twenty year span from $1983-2002$, only 256,868 new units were built (WRAP 2010).

The reason for the large decline in the construction of affordable units was due to HUD's average decrease in budget authority from the early 1980 s to the early 2000 s. The HUD budget authority for low-moderate income housing assistance peaked in 1978 at more than $\$ 77$ billion dollars, and by 1983 it was down to $\$ 17$ billion (Figure 1). For the next 24 years, from 1984-2008, HUD's annual budget authority for low-moderate income housing assistance averaged \$23.4 billion (WRAP 2006). In 2009 there was a significant spike in HUD's budget due to stimulus funding at the onset of the recession, but has since 
decreased. The declining ability of HUD to fund low-income housing assistance has severely hindered homeless peoples' capacity to find affordable housing. What is more, existing housing declined from its peak in 1978 because of the demolition of public housing stock as well as conversions of public housing to private housing.

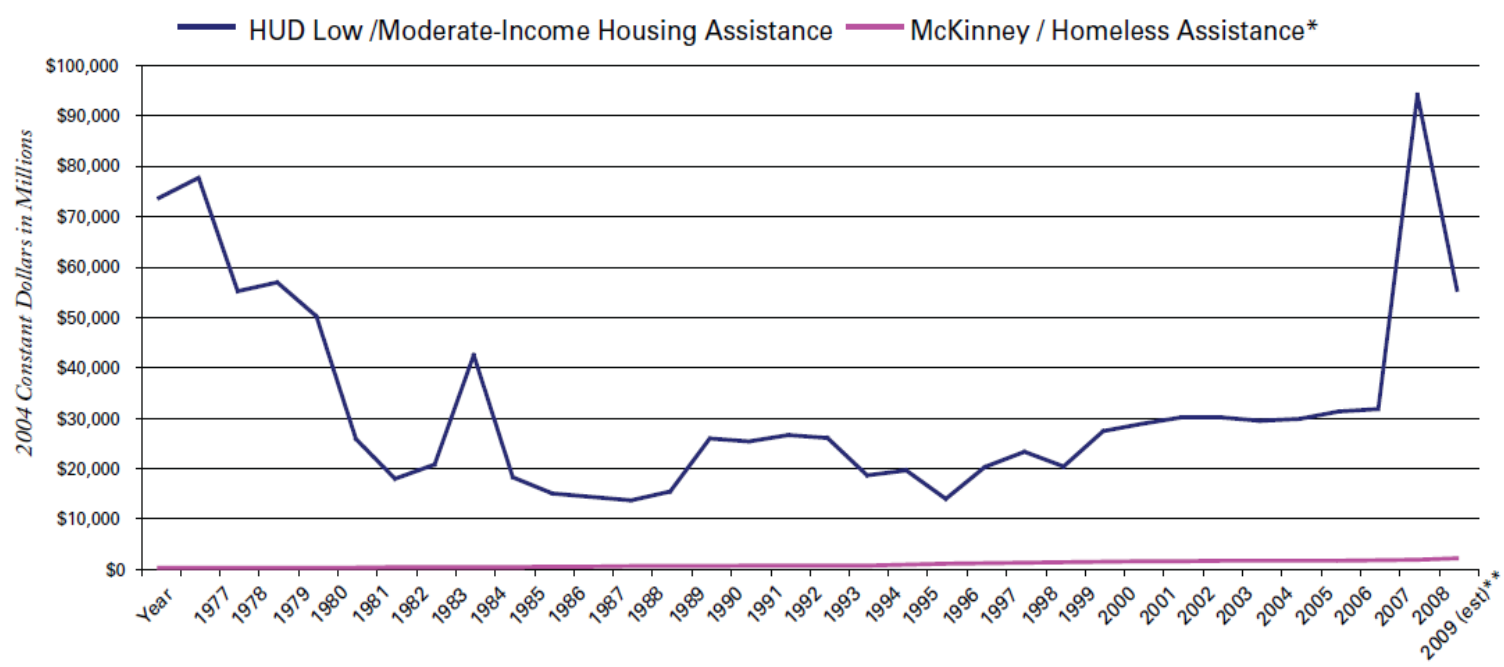

Figure 1. HUD budget authority and homeless assistance from 1976-2009. Source: WRAP 2010.

Federal spending on housing assistance, almost completely from HUD, is needed along with other assistance efforts to make an impact on the shortage of affordable housing units. A shortage in affordable housing units is creating a larger barrier for getting the homeless in to stable housing. This disparity is embodied in the growing socio-spatial inequalities of urban areas all over the world. Portland is also experiencing the effects of affordable housing availability, as well as a weakened social service network. The case of Portland is discussed in the next chapter. 


\section{Chapter II: Impacts on U.S. Cities: The Case of Portland}

Whether Portland's city government operates with an entrepreneurial approach to development is difficult, if not impossible, to quantify. One indicator of entrepreneurialist influence in urban development, however, is the abatement of construction and funding for affordable housing. Closely related to this is an absence of funding for emergency shelter spaces. Imbalances in both affordable housing and emergency shelter availability in Portland has resulted in the increase of homelessness.

The reasons for shifting governance approaches are multiple. Federal funding is not as prominent as it once was. This alone has hindered cities' ability to maintain services for the poor. These federal funding cuts put fiscal pressure on local and regional urban governments. As a result, service provisioning became more difficult to implement for cities. In the Portland metropolitan area, for example, City and County service jurisdictions have been rescaled, affecting the provision of housing and other homeless services.

\section{Fragmented Service Jurisdictions}

In August of 1984 the City of Portland and Multnomah County entered into an intergovernmental agreement (IGA) which divided responsibility over the provision of core urban services. Based on an audit by the City of Portland Auditor's office (2013), the purpose of this agreement was twofold. The first reason was to provide more efficient services to people living in unincorporated Multnomah County. It was thought that the City should be able to cover the growing areas on the peripheries of the city of Portland proper. The second reason the IGA was enacted was to address the financial problems 
Multnomah County was facing in the early 1980s. When enacted, this agreement effectively divided responsibility over key urban services, most critically for this research, housing and mental health services.

The original agreement has not been well defined by either entity, as many terms within the agreement have vague definitions. This lack of definition obfuscates which party is responsible for providing particular services. To be sure, the City Auditor's Office (2013) found that this agreement "cannot be used to obligate either party to perform specific services, nor do they clarify each jurisdiction's core services" (p. 1). This is problematic in that, thirty years after the agreement was implemented, core services still cannot be defined by either party involved. This means that each entity is unclear as to where different service jurisdictions begin and end.

The nebulous structural and geographic terms of the agreement have had some impact on the delivery of services that assist the homeless. Over the thirty-year course of the agreement, two services in particular have affected service provision for the homeless. The first is directly related to housing: the County was originally responsible for the delivery of housing services, including homeless assistance, at the signing of the agreement. As the City of Portland (2013) notes, the "increasing demand for services, along with funding reductions from Federal sources has placed pressure on housing program funding" (p. 6). The second involves police interaction with the mentally ill. At the time the agreement was made, the County was responsible for mental health services. Cuts from the State have reduced County response to mental health crises, however. Instead, when there is an altercation that involves mentally disabled individuals, the City 
of Portland Police are often first responders. Not only does this deter police from other potential activities, but the police are not trained mental health professionals. The effects this can have for the mentally disabled who are approached by the police can lead to inappropriate and unjust treatment. This can affect the treatment of mentally ill homeless who are involved with police interactions.

The underlying concern that arises out of the conflicted nature of the IGA, however, is that there is little reassurance that the City or County is aware of their respective responsibilities for providing particular services. A 1997 multijurisdictional audit on housing programs found a "fragmented nature and conflicting priorities of housing programs in Portland and Multnomah County" (Office of City Auditor). Another report in 2008 found similar problems with little change in service jurisdictions. The uncertain terms of this service agreement may have hindered access to housing assistance for homeless and mentally ill individuals in Portland and greater Multnomah County in critical decades for social service support.

The confusing terms can be seen citing an example from the document Home Again- A 10-Year Plan to End Homelessness, an initiative to end homelessness by 2015 in Multnomah County. In this document, the County's responsibilities are described as for "planning and contracting for services to all homeless population countywide, except single adults" (Citizens Commission on Homelessness 2004, 9). Additionally, the County contracts their homeless services from non-profits in six geographically separate districts. Whereas the City's Housing Bureau is responsible for "planning, coordinating, funding, and evaluating services for homeless adults countywide" $(2004,9)$. Furthermore the City 
provides funding for rental assistance and homeless youth services through a "formal agreement" with Multnomah County $(2004,9)$. The overlapping nature of homeless and housing service provision has been a source of confusion for both political entities. Coupled with other structural barriers, the City of Portland and Multnomah County's ability to assist the homeless is certainly fractured. This political fragmentation is complicated with financial support for services seeing new lows. This is most marked when looking at the availability of affordable housing.

\section{Affordable Housing Shortages in Portland}

While other cuts to federal welfare spending will be difficult, the main problem facing the mitigation of homelessness in Portland is the shortage of affordable housing units. In the context of Portland's housing market, there has been an increase in affordable housing for renters at the 50-80 percent of Median Family Income (MFI) levels. In fact there is a surplus of units for renters at this level in Portland (Weinstock 2014). Conversely, there is a severe shortage for those renters whose income is below 30 percent MFI. Based on 2010 U.S. Census data, 33,410 extremely low-income households compete for about 11,500 affordable apartments in Multnomah County (Weinstock 2014). Thus there is a shortage of 20,000 affordable units in Portland and nearly 23,000 in greater Multnomah County for extremely low income renter households at or below $30 \%$ MFI.

The availability of housing is also predicated on its affordability. Since 2000 , both housing prices and rents have increased more than incomes in Multnomah County (City of Portland and Multnomah County 2013). This is yet another factor that makes housing 
difficult to obtain for individuals and families with very low incomes. And while the City of Portland has been increasing the number of affordable housing units in new developments recently, these units are mostly open to the market. In other words, the majority of these units are not reserved and thus guaranteed for those with low incomes.

The difficulty in obtaining housing in Portland is evident in the vacancy rental rate of the Portland metropolitan area. Among the largest 75 metropolitan areas in the U.S., Portland currently has the second lowest vacancy rental rate at 3.1\%, one-tenth away from the lowest vacancy rental rate of San Jose, CA. (U.S. Census 2014). Since 2010, the vacancy rental rate in Portland has gone from $8.2 \%$ to its current rate of $3.1 \%$. With such a tight rental market, low-income individuals are forced to compete to find open units. The small amount of units and quick turnover this type of rental market creates puts homeless individuals looking for affordable housing at a huge disadvantage.

Currently there remain few answers to how funding for the construction or preservation of subsidized affordable housing units will be acquired. The City of Portland does mandate a particular percentage of affordable units in all new high-density housing construction. But this is not enough. It is the absence of affordable housing units for lowincome renters that sustains an increasing homeless population in Portland.

The notion that federally subsidized housing units will be constructed to meet this need is unlikely to happen, however. Even if budgets were parallel to those of the late 1970s, the overall eradication of public housing over the last 30 years would not likely meet the contemporaneous demand. Therefore, some cities and advocacy groups have begun to explore alternate means for sheltering the homeless and underserved 
populations. This can mean transcending traditional channels of homeless assistance, like subsidized public housing, to meet the immediate need for shelter. These alternatives are predicated on equal access to resources. Discussing equal access to fundamental resources has been framed through the concepts of "right to the city". A discussion of this concept and its application within urban geographies of homelessness follows. 


\section{Chapter III: Literature Review}

Alternatives to providing shelter for the homeless have become critical in view of decreasing government expenditures. Yet there is little effective political and economic recourse for organizing such services because of restrictions on land usage that preclude such spaces within cities. Additionally, as the welfare state has been diminished and restructured to the point of general economic instability for the poor, it is impractical to believe funding levels will recover to what they once were. Even if they did return to the higher levels of the past, the situation in major cities in the North America is more severe than it has ever been. It will take more than substantive funding to reverse this trend. It is important, then, to consider what exists now in lieu of substantive funding for homelessness. The ideas found in the "right to the city" concept are useful for thinking about such alternatives.

\section{Right to the City}

The "right to the city" concept originated with French philosopher/sociologist Henri Lefebvre in 1967. His initial writing on the subject appeared in his book by the same name, Le Droit à la Ville. Lefebvre saw the right to the city as "the right to freedom, to individualization in socialization, to habitat and to inhabit... the right to the oeuvre, to participation and appropriation" (1996, 173-74). For Lefebvre, the right to the city is not a legal right, such as is embodied in ownership of property or citizenship. Instead, it is a moral appeal to people's participation in, or rather not to be excluded from, urban life. The 'urban' for Lefebvre is a place of encounter, an assemblage and 
negotiation of difference, prioritizing the use value for inhabitants through collective participation in making the spaces of the city.

Lefebvre presents his thinking on right to the city as a critique on the systemic contradiction of capital's destruction and intensification of the economic processes of urbanization. For Lefebvre, this is not how cities should be lived in nor organized. It is with this perspective, then, in which he asserts that the constitution of an 'urban society,' a city managed collectively by urban inhabitants, can only be realized through the working class. It is the working class that can "contribute to the reconstruction of centrality destroyed by a strategy of segregation and found again in the menacing forms of centres of decision-making" (p. 154). Although he recognizes that urban reconstruction is not solely on the shoulders of this class, without them there is no urban society in the Lefebvrian sense.

Extending the notion that the working class' inclusion is seminal for the renewal of urban society, claiming rights to the city also signifies the rights of urban dwellers to "appear on all the networks and circuits of communication, information, and exchange... this depends... upon an essential quality of urban space: centrality" (p. 194-95). For Lefebvre, to exclude urban dwellers from the centre of the urban, not solely by physical proximity, is to exclude them from urban civilization. A right to the city thus "legitimates the refusal to allow oneself to be removed from urban reality by a discriminatory and segregative organization" (p. 195). Therefore, to refuse to be excluded from urban space and society is seen as one's right to participate in the production of urban space; to appropriate the social space of the urban to maximize its potential use value. 
Today, "right to the city" is an indefinite term. It has come to represent many things about injustice in the city and is read and understood from multiple perspectives. Indeed, Marcuse (2014) identifies at least six different readings of Lefebvre's "right to the city". These different readings have identified spatial elaborations of the concept (Soja 2010, Purcell 2008), socio-economic understandings (Brenner 2011, Harvey 2008, Mitchell 2003), and the pursuit of more democratic urban societies (Purcell 2013). All of these readings, however, are inherently political in their applications.

It is the democratic reading of "right to the city" that is perhaps most relevant to the case of R2DT. Purcell (2013b) suggests that "right to the city" is a political project, one which "challenges a neoliberal model of governance, but more generally it also urges us to chart a path to a radically different urban society beyond the state and capitalism" (p. 311). The tool for this is democracy, but not in the liberal-democratic sense. Lefebvre (2009) asserts that "democracy is nothing other than the struggle for democracy" (p. 61).This struggle is inherently political, as it runs counter to how we view rights and citizenship today. Democracy for Purcell (2013b) is the process of living together and managing affairs for oneself. Pertinent to this seemingly quixotic notion is that achieving democracy is not an end state; rather it is a process that is only ever continuously becoming.

It is thus necessary to recognize the struggles of urban society that is often fledgling at the margins, but sometimes right in front of us. It is important to help these instances of struggle to continue. Purcell (2013b) requests that we "begin from the understanding that our power is already active and alive" (p. 322). In the case of 
homelessness, we see it in everyday urban life. Often the homeless struggle to appropriate urban spaces for themselves simply to survive. They are excluded from many spaces, public and private. Thus, when instances of self-organized homeless spaces present themselves, it is worth looking deeper at their potential for becoming democratic. To put it differently, it is useful to assess a homeless rest space's progress in legitimizing itself amidst political and economic conflict.

Indeed it is necessary to illustrate and assess how these very desperate actions of the economically marginal are being organized and what needs they are servicing. Today it does not seem reasonable to expect that a reversion to a Keynesian welfarist model would completely undo the situation of the nation's impoverished. Even if such a federally-supported welfare model was reinstated, would the applications of such funding penetrate the pervasive socio-spatial and socio-economic inequalities present in today's cities?

While there is no certain path to take to mitigate the increasing problem of homelessness, we know what has not been working. Therefore, it is vital for leaders of cities, as well as those who reside in them, to support alternative paths to our traditional means of mitigating homelessness; ensuring the "right to the city" for all residents. I begin the next section by tracing various approaches to studying the geography of homelessness to provide the context in which my research fits within this discourse.

\section{Geographies of Homelessness}

Geographic research on homelessness in the past 30 years has illuminated many issues. Perhaps the most foundational research in this realm was Michael Dear and 
Jennifer Wolch's recognition by the mid-1980s of the particular urban spatialities resulting from welfare restructuring and large-scale deinstitutionalization of mentally ill individuals. They argue that homeless people gravitated toward particular sections of cities where services they depended on could be found (Dear and Wolch 1987, Wolch and Dear 1993). As more individuals migrate to these service-filled sections of the inner city, more services follow. They use the term "service-dependent ghetto" to signify this process where individuals will instinctively concentrate geographically to receive needed support.

The continued closings of single-room occupancy hotels and other low-rent options for individuals in "skid row" areas of inner cities bourgeoned as the effects of urban renewal programs across U.S. cleared massive low-income districts for redevelopment. This effectively created zones of discard, with increases in the number of individuals living on the street. People without housing began aggregating around service clusters, with fewer places to take shelter in. And while there were concentrations of homeless around services, these individuals were still using other public spaces throughout the city.

By the late 1980s, the poor, as well as other socially marginal groups, began to be stigmatized as unacceptable inhabitants of particular urban spaces (Takahashi et al. 2002). Largely this meant that poor individuals using public space were still deemed "out of place" (Cresswell, 2001) when they had every right to be present in those public spaces. Cities began sweeping the homeless out of public spaces through a variety of means. New sets of urban policies increasingly focused on dispersing these 'abnormal' 
groups from public and private downtown areas so as to become more attractive for capital and private investment.

Don Mitchell considers this new wave of urban spatial policies as the “annihilation of space by law" $(1997,305)$, where poor individuals are increasingly pushed out of the public spaces they use in the process of living their everyday lives through exclusionary land use policies. For Neil Smith (1996), part of these legal processes of displacement resulted from the slower processes of gentrification as well. Particularly in New York City, the decreasing options for low-income people to find housing as "urban pioneers" moved in to disinvested neighborhoods, added to the host of exclusionary restrictions of urban spaces for the poor. These punitive urban policies continue to be problematic for low-income residents looking for equal access to the amenities of urban centers.

For nearly two decades, homeless geographies largely detailed the multiple forms of socio-spatial exclusionary tactics used on the poor. DeVerteuil et al. (2009) agree that two decades of these legal measures have made simply existing in urban spaces quite difficult for the homeless. They argue, however that a punitive focus to homeless research largely homogenizes the homeless experience. They suggest little is learned about the homeless themselves and how they experience these changes. To overcome this, they propose undertaking a more holistic, "poverty management" style approach that considers the multifaceted nature of homeless experiences throughout space. 
Along these lines, Steve Herbert and Katherine Beckett's work (Beckett and Herbert 2010, Herbert and Beckett 2010) recognizes the deleterious nature of exclusionary policies which Mitchell criticizes, while offering further understanding of the particular effects of an individual's "banishment" from public spaces. Their ethnographic work with the homeless shows that punitive land-use restrictions are not only difficult for the homeless to accept, but are nearly impossible to abide by given different individuals' attachment to places for services and due to their multiple social ties. Their larger point is that promoting exclusionary policies for the poor as a solution to urban development leaves the essence of the plight of the poor untouched. Thus, they advocate through deeper ethnographic research, we can understand how policies affect different individuals in urban spaces.

Tony Sparks (2010) also considers the intricate nature of the spatiality of homeless camps within urban public spaces. He suggests that homeless camps, as public displays of poverty, are necessarily subject to public gaze. The production of private homeless spaces such as a tent city, then, is a means through which they resist the stigmatization of homeless as 'other' by contesting the notion that homeless have no rights to privacy as highly visible subjects of poverty. He highlights why privacy is an essential aspect for the homeless in the production of place-making in the city.

A significant portion of homeless geographies research focuses on the United States and Canada. There has been significant comparative research from all over the world that has contributed to a more nuanced understanding of this problem, however. Jurgen von Mahs (2011) uses a relational perspective on the "Americanization" of urban 
social policies to get a better understanding of how industrialized nations differ in their urban policies that affect the homeless. He argues that even countries with longer and more generous traditions of social welfare policies are turning to punitive as well as "softer" measures to exclude the poor from urban spaces as U.S. cities have done for decades. He suggests that overcoming these socio-spatial exclusionary barriers must be spearheaded by local welfare states which are more adaptive at lowering service costs for individuals experiencing homelessness (2005). Most important, he argues, is highlighting successful policies and service provision that nuance the aforementioned punitive research over-representing the homelessness literature. This position does not necessarily idealize a reversion to a welfare state from the past, but seeks moments of successful service provisioning alongside a welfarist approach.

Ananya Roy (2003) also uses comparative methods to understand the different conceptualizations of the homeless living informally in the U.S. and those living informally in India. She calls attention to the American paradigm of "propertied citizenship" that makes few concessions for the poor without "sufficient" housing, whereas a developing world paradigm does not marginalize the poor as such. Rather, the poor living informally in India are legitimized through their claims to such informal types of shelter. Therefore, globally situating the increasing occurrences of informal living in the U.S., i.e. tent cities and squatting, can help deconstruct the normative American notion of property and citizenship to help decriminalize or even conceptually legitimize the informal modes of living increasingly becoming part of the American urban landscape. 
The geographies of homelessness literature has changed significantly over time. The foundation of this body of work recognized that homeless individuals are highly concentrated in urban areas. Further research indicated that particular urban land use policies negatively effect homeless individual's use of urban spaces. And most recently a more nuanced understanding of how homeless individuals experience urban spaces and constraints within them has begun. The first part of my own research reflects the structural barriers to homelessness at the hand of the State and private capital. This understanding of the welfare state and entrepreneurial approaches to governing cities is, I argue, necessary to understand why homelessness is increasing in cities all over the country. However, it is equally important to illuminate how the homeless are managing these difficult barriers and what currently exists that gives hope to such a daunting problem. Therefore, assessing what alternatives currently exist alongside a defunded welfare state, and how the value (exchange) of urban spaces is being contested by groups marginalized by a system of propertied citizenship, is an important advance in thinking about alternatives to an increasingly apparent homeless problem. 


\section{Chapter IV: Right 2 Dream Too}

Right 2 Dream Too is a non-profit advocacy organization that has been operating a rest area under the same name. It is the rest site that is most identified with this name, however. Over the course of its three years of operation it has served hundreds, if not thousands of individuals. And it is by traditional standards a unique model for service implementation; primarily one that is based on self-organization without the authority or financial backing of the State.

It is not only a homeless rest space, but a collective of individuals who have disparate backgrounds in organizing and activism. Those staying at the site are first and foremost, using the space to sleep and stabilize. But they are also a group that is active in calling attention to the state of homelessness in the city and access to affordable housing. As such, their occupation of the rest site reflects Lefebvre's notion of access to the 'urban'. Again, he suggests that all have the "right to the city," but not in the juridical sense, however. He meant that everyone has the right to produce urban space through the participation and organization of planning urban spaces. In this sense, the R2DT residents have been claiming rights to the city.

They are calling for equal access to shelter by contesting the notion that

citizenship is necessarily defined by the ownership of housing. While this is perhaps not a conscious contestation, R2DT addresses the main tenets Lefebvre laid out. They have appropriated space that is not zoned for transitional housing to bring attention to and call for equal access to shelter. Along with their participation with the City, they have been legitimizing their right to occupy and produce that space to accommodate unsheltered 
homeless individuals. They are then promoting the use value of that space over its potential exchange value.

This is only a start, however. Realizing rights to the city, or to produce more equitable urban space, is not straightforward. Therefore, it is important to understand both how this rest site operates and the experiences of those using the space. Broadly this research looks at why R2DT is an important place in the lives of the homeless. I am interested in how the rest site is helping individuals manage their times of difficulty. More specifically, I am looking at how this service is connected with, or distinct from, homeless service provisioning in Portland and other cities. As this rest site does not exist in a vacuum, it is important to understand relationally how lives are lived outside of this space and how lives unfold throughout the city. Lastly, I inquire as to how this informs our understanding of the geographies of homelessness.

\section{History of the Site}

R2DT is a non-profit advocacy organization that has been operating the rest area under the same name in downtown Portland since October 10, 2011. It sleeps 60 to 80 people each night, which fluctuates by the changing demographics of its users. There are both members and overnight sleepers who stay at the site. Members start out as overnighters and contribute a variety of help involved with the daily operations of the site. Overnighters who are interested in staying longer and becoming a member are approved by vote of the current members. Some overnighters only use the space for a few days. Overnight sleepers must come to the rest site to sign up every night to guarantee a 
spot. They are allowed to sleep within the site from 9:00pm until 9:00am the next morning. Overnighters then sign out and do not leave personal belongings at the site.

R2DT is located on the northeast corner of West Burnside Street at Northwest Fourth Avenue (Figure 2). Adjacent to the China Town gate in the Old Town neighborhood, it is a site known for its colorful series of doors that conjoin to a fence (Figure 3). It is a space that affords the homeless a safe, more secure place to sleep. It sits on privately-owned property, is leased for one dollar per month, and functions as a site for housing transition, although it is not legally defined as such. It has also been under duress nearly since its inception with the ongoing threat of imminent relocation.

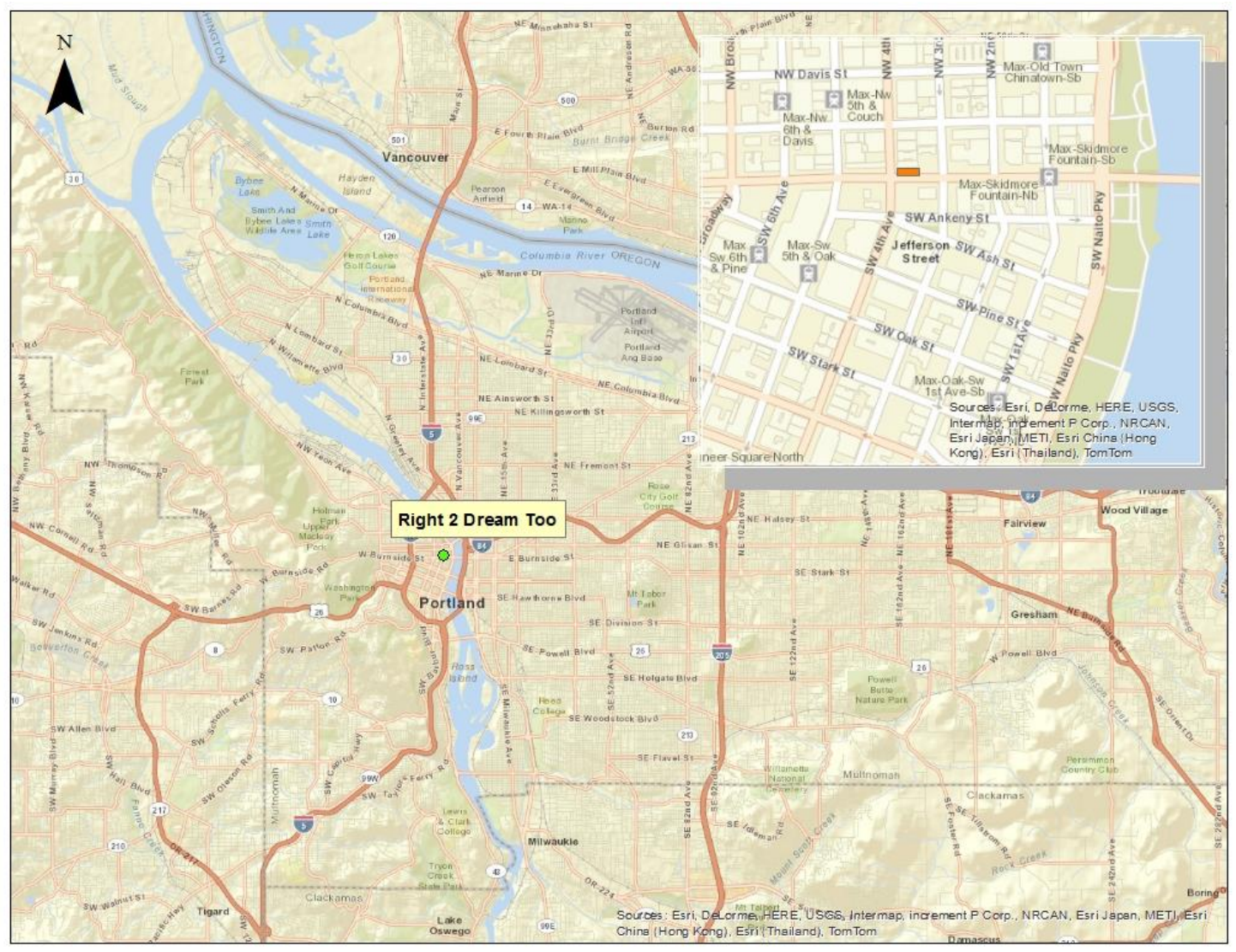

Figure 2. Location of R2DT in downtown Portland, Oregon. R2DT is represented in orange within the inset. 


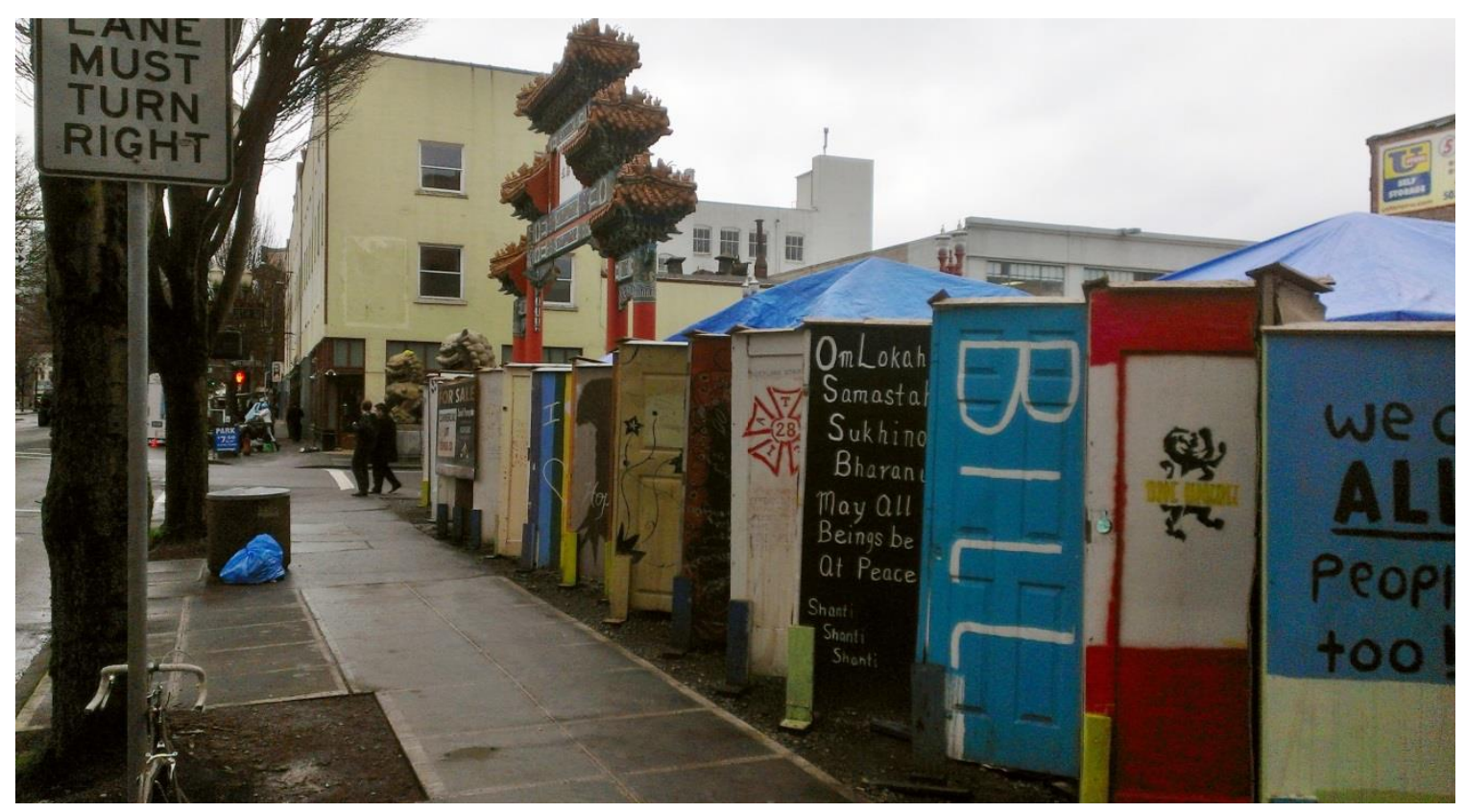

Figure 3. R2DT's doored-fence looking west on Burnside Street.

The Old Town neighborhood has long been host to the economically marginalized of Portland. As the oldest neighborhood in downtown, it has seen remarkably little socioeconomic change over the last century. In the early 1900s, it was a "neighborhood of lodging houses and flophouses, second hand stores, missions, saloons, brothels, and employment agencies. At its height between 1900 and 1925... Portland [had] proportionately one of the largest skid roads in the country" (Abbott 26, 2001). As the growth of downtown Portland proceeded through urban renewal developments in the 1950s and 1960s, industrial employment opportunities once concentrated in this neighborhood started disappearing.

As early as the late 1960s and early 1970s, West Burnside Street and the surrounding neighborhood was considered the "skid row" or "skid road" of Portland". It

\footnotetext{
${ }^{6}$ Skid road and skid row are often used interchangeably. By one account, "skid road" was the original use of the term. It originated out of the Pacific Northwest where loggers would skid logs down roads. Burnside
} 
was deemed crime-ridden, filled with itinerants, alcoholics, and was predominantly comprised of low-income housing with an abundance of single room occupancy (SRO) hotels (BNC 1972, CCC 2014). Social services arrived in the neighborhood in the early 1970s to address these problems.

Today a dense cluster of social services remains that assist low-income individuals, many of which are particularly geared toward the homeless. Dear and Wolch's (1987) renowned research on Los Angeles recognized that homeless services often cluster around one another due to the availability of cheap housing accommodations, coupled with an abundance of health and welfare services. Lee and Price-Spratlen's (2004) more contemporary analysis of census data on metropolitan homelessness found that homelessness is geographically uneven in the U.S., in that homeless populations are often resigned to inner city areas. Even more recently Herbert et al. (2010) reaffirmed that the homeless, and the various services that cater to them, are often spatially-concentrated, and often in inner city neighborhoods. Spatiallyconcentrated, low-income service clusters have been found consistently in inner cities for decades.

In Portland, as early as 1972, the Burnside Neighborhood Committee (BNC) was aware of the deleterious effects of relocating the concentration of social services aimed at low-income individuals residing in the Old Town area. In a statement to the City of Portland, the BNC asserted that "scattering individuals out around the city only masks

was such a street in Portland. It also happened to be where loggers lived while working. When temporary labor such as logging dried up, workers might remain living in cheap housing (Distilled Publishing 2007). 
their social and health problems and causes extreme distress and social displacement to the individuals involved" (BNC 1972, 2-3). Today, municipal leaders in charge of relocating R2DT are aware of the cyclical relationship of the homeless with these clusters, further nuancing the decision of where to move the rest site.

The relocation efforts of R2DT are compounded by the curious history of the land usage and its ownership. In the early 1980s, its owner bought the building on its current site and opened an adult bookstore. That business remained until 2007, when the building was structurally damaged to the point of inoperability. The building was demolished in 2008 and sat as an empty lot until 2011. It was at this point the same owner attempted to fill the vacant lot by establishing a food cart pod with a few food carts. The City of Portland did not allow this either and fined the owner for hosting food carts on an unpaved surface. The owner was then restricted from paving the lot as the neighborhood zoning codes did not allow for such land uses.

Then in autumn 2011, as Occupy Wall Street (OWS) protests were beginning, houseless individuals in Portland, unconnected with the OWS protests, began setting up tents on the lot. This was partially in response to a rhetorical question stated by the site's owner over the radio, suggesting that if a business would not work on this lot, then maybe the homeless could sleep there. Responding to this invitation, Right 2 Dream officially moved onto the site at West Burnside and Northwest Fourth Avenue on October 10, 2011 in small iterations. 
One month after it opened its doors the City of Portland issued the site with a notice of code violations. The first code violation of the property, in regard to Oregon Administrative Rule (OAR) 918-650-0005(12), defines the site as a "recreation park" (OSS 2012, n.p.). The State of Oregon defines a recreation park as "an area designated by the person establishing, operating, managing or maintaining the same as being for picnicking or overnight camping by the general public or any segment of the public" (OSS 2012, n.p.). Under this definition, then, an operating license is required from the property owner.

The second violation was due to R2DT not obtaining a building permit to erect its fence. Section 33.445.320 of Portland Zoning Code requires a building permit to be obtained for fences higher than six feet in an historic overlay zone (PBP 2013). The doors that comprise the fence at R2DT are slightly taller than six feet. As long as R2DT continued to allow people to sleep at this site, it violated City Code, and monthly enforcement fees continued to accrue.

Although R2DT recognized it was under violation of these two codes, it did not feel the designation of "recreation park" was valid for the space. R2DT claimed that, under this code, a recreation park is intended for recreational picnicking sites, or recreational overnight camping sites, not for the housing that is being provided for homeless individuals. Instead, they requested the site be designated a "transitional housing accommodation" under Oregon Revised Statute 446.265 (ORS 2011). This law allows each Oregon municipality to establish two campground sites for use in providing transitional housing accommodations. This particular designation is limited to those 
individuals who lack permanent shelter and cannot be placed in housing. Portland has established one transitional housing site already: Dignity Village in the northeast quadrant of the city. Therefore, designating R2DT as the second transitional housing site was, and remains, an option for the City. If this were to happen R2DT could continue operating as a rest area along with the cessation of code enforcement fees.

In December 2012, R2DT received legal representation which resulted in a lawsuit against the City. In this complaint, R2DT argued that the continuing fines and assessments from the City interfere with their "right to the quiet enjoyment of such property under their lease" (M. Kramer, R2DT Attorney, March 2013). More substantively, they argued that the City erred in their assessment of the rest site as a recreational campground. Instead, R2DT's attorney argued that City bylaws did not even contain any legislation governing an urban homeless site in Portland (Korn 2012).

Additionally, the lawsuit was intended to force the City into the decision-making process surrounding the property's usage after months of fruitless conversation about the legality of the site.

It would take another nine months of little-to-no public discourse surrounding the operation of the rest site for any action from the lawsuit to transpire. In September 2013, the terms of the negotiations changed significantly, as did the general narrative of the City's position. In early September, the city commissioner responsible for housing, Amanda Fritz, fostered a deal with R2DT that would drop the rest site's lawsuit against the City, and in return the City would find an alternative site for its relocation. On top of that, the City would dismiss the nearly $\$ 21,000$ in fees accrued from the site's code and 
land use violations (Settlement and Mutual Release 2013). While this agreement relieved the financial burden for R2DT, it did not designate the rest site as a legal rest area.

The agreement then gave R2DT 30 days to cease and desist all camping activity on the property in perpetuity. Simultaneous to the signing of this agreement, though, the City had found a potential site for the rest area's relocation. The newly proposed site, located under the west end of the Broadway Avenue Bridge at NW Lovejoy Street, was owned by the City of Portland's Development Commission (PDC). When this announcement became public, there was wide-spread pushback against the relocation. The majority of the reactions against this move came from the association of the neighborhood in which the site was proposed to move into, the newly gentrified Pearl Neighborhood District. In addition to neighborhood resistance to the proposed relocation, a private development agency that was in the midst of developing a new hotel one block from the proposed site also argued against the move. These two groups, and others against the move, were concerned with the lack of transparency in the decision-making surrounding the relocation process. It was argued that the City was forcing the relocation with no public input.

To counter the claims that the City was acting privately on the relocation decision, an open city council meeting was held in early October 2013 to allow for public input. The event was well attended and reflected the deeply divided opinions of where R2DT should be or should not be located. The meeting ended with little closure, with the city council deciding to further delay the official relocation vote. While the delayed vote was to be for only one week, the deadline for R2DT to move off its original Burnside site was 
to expire at the end of October. Therefore, without a council vote, again the rest site's move was extended, giving R2DT 60 days longer to remain at its original location (Schmidt 2013). Despite there being no vote for relocation, what did transpire at this meeting was a general narrative of support for the service that R2DT had been providing at that point. This sentiment came not only from some members of the city council and the mayor, but also from some of the members of the groups originally opposing the move into the Pearl District neighborhood.

Approaching the end of the 60-day extension to relocate the rest site, there were still no alternative sites being considered. By mid-December 2013, Mayor Hales then took over from Commissioner Fritz as lead in the relocation process and proposed another site for R2DT to relocate. This time the site was inside a vacant warehouse, just a few blocks away from its original location in the Old Town neighborhood. While this site was being analyzed, Mayor Hales wrote a letter to the Old Town neighborhood association assuring them that R2DT would only operate in the warehouse temporarily, as to give the City more time to find a more suitable site. The significance of the letter underscored not only the City's desires to see R2DT moved off of its original location, but also making clear that the Old Town neighborhood was not the appropriate neighborhood for such a service. By early January the proposed warehouse site was also rejected, primarily due to the significant cost to the City in housing R2DT in the warehouse for only 15 months (Theen 2014).

After the second attempt at relocating the rest site fell through, R2DT continued to pressure the City by reiterating the agreement they had originally made to find an 
alternative site for relocation. By mid-February 2014, there was still no proposed site on the table for R2DT. At this time, an unexpected decision was made surrounding the negotiations. R2DT was awarded $\$ 846,000$ by the PDC to buy, lease or rent a property that would fit the appropriate zoning regulations (Theen Feb. 19, 2014). The large sum of money came from the sale of the first proposed site for relocation at west Broadway Avenue and NW Lovejoy Street. The developers originally in opposition to R2DT's move to this location purchased the land from the PDC for around 1million dollars; around $\$ 142,000$ for the actual land, leaving $\$ 846,000$ essentially as a gift for R2DT to help in their search for a new site.

The money awarded to R2DT, and controlled by the City, was used to hire a real estate broker who would assist in finding an appropriate site for the rest area to relocate. The money will mostly be applied to a lease or for purchasing the new site once it is found. In late February, a list of 21 potential sites for relocation was proposed. For the first time in the relocation process, a set of criteria was established for where the site could relocate. The two criteria, agreed upon by the City and R2DT, were tenuous at best. The first was that the site be within one and half miles of the Portland Building in downtown Portland with the second suggesting the site needed to be "close to public services and transportation" (Theen, Feb. 27 2014). While largely unexplained, R2DT was the entity for establishing the one and half mile boundary around the Portland Building, ostensibly to remain central to the core of downtown.

By May 2014, most of the 21 sites were rejected as potential spaces for relocation. The reasons have been many; they are located outside the one and a half mile radius, they 
are on contaminated sites, or city commissioners have asked to have a particular site removed for various reasons. In late June another major transaction took place. The property's owner accepted an offer from the PDC to purchase the property for $\$ 1.5$ million (Theen, 25 June 2014). This however, did not result in an automatic closure for the rest site. Within the settlement there is a 30 month due-diligence period in which the owner of the property has the full amount of time allotted to vacate the property. This puts R2DT in a precarious position. If the owner were to take the total sum of the purchase, R2DT would need to vacate the property. On the other hand, R2DT could possibly remain there until the end of the 30 -month period; set to expire at the end of 2016. 


\section{Chapter V: Methods}

Multiple approaches were used throughout this research. A significant portion of data derived from textual analysis of the geographic literature on homelessness and "right to the city," as well as of media coverage of R2DT. My primary data came from substantive interviews with R2DT users as well as directly observing the interactions in this space. Direct observation was used to help describe the site and situation of the rest space. The goal for the analysis of the interviews and observational data was to make sense of individual's experiences while using the rest site. To get a first-hand account of individual's experiences using R2DT indicates how the space is used for more than simply an emergency shelter, but also how the site is produced as a social assemblage with multiple spatialities.

To initiate my presence at the rest site, I attended a community meeting at R2DT to introduce myself and describe the intentions of my research. It was at that meeting in which members as well as a few of R2DT's board members said they would be willing to have me conduct interviews for as long as I needed. The interviews spanned from early August to early October, 2013. The actual process of getting an interview was not routine (Appendix A). Some days when I was on site I conducted multiple interviews. There were days where I conducted only one interview. And there were a handful of days where I did not get any interviews. Direct observation was also part of the process while waiting to meet with someone for an interview or on days that I could not get an interview.

In total I conducted twenty-eight semi-structured interviews. I established a set of leading questions for all interviews before any interviews were conducted (Appendix B). 
All interviewees were asked the same questions in the same order and were only recorded with hand-written notes. All interviewees read and signed the appropriate consent forms before any questions were asked. I conducted the interviews in various spaces. A majority of the interviews took place within the rest site or on the sidewalk just outside of the rest site. Three or four interviews were conducted several blocks away at a site of the interviewees' choosing. The interviews were not pre-scheduled and the majority of the interviewees were approached without prior contact. Therefore, the interviewees comprise a convenience sample, and may not be representative of homeless individuals as a whole.

Fourteen interviews were with R2DT members, or those who stay at the site permanently. The other fourteen interviews were with over-night users, or those who stay at the site for only twelve hour periods. Twenty-one people identified as male and seven identified as female. The interviewee ages ranged from twenty-four to seventy-four; forty-six was the average age. The number of years the interviewees had been homeless ranged from seven days to twenty-eight years; slightly less than four years was the average. The length of time the interviewees had been staying at R2DT ranged from two days to almost two years, while the average tenure was four and a half months.

\section{Data Analysis}

A thematic approach for the data analysis was used to organize and identify shared experiences of the individuals at R2DT. Braun et al. (2012) describe a thematic approach to data analysis as "a method for systematically identifying, organizing, and 
offering insight into patterns of meaning (themes) across a data set. Through focusing on a meaning across a data set,[it] allows the researcher to see and make sense of collective or shared meanings and experiences" (p. 57). I therefore am not looking to find idiosyncratic experiences of all individuals staying in this rest space. Instead, I seek to find commonalities related to my research goals. There are three main goals for this research: to better understand individual's relationship with place and space, to understand the situation of R2DT within the downtown landscape, and to assess how the social interactions within the site has produced the space that exists there today.

This particular approach entailed a variety of coding, grouping, and reorganizing decisions. The process began by transcribing interview data into individual documents. Once in a separate document, each interview was read completely before any codes were applied. During the initial stage of data coding, each interview was read line by line. The intent at this stage in the coding process was simply to identify and mark various meanings in the data. Line-by-line analysis and initial codes were applied to all twentyeight interviews. This style of thematic coding is similar to the techniques described in grounded theory by Charmaz (2006), but does not however, go on to produce theory as suggested in true grounded theory. Instead, finding patterns and providing socio-spatial insight into the lives of homeless individuals was the focus for using this analytical approach.

Once all interviews were initially coded, each interview was read through for a second time, now focusing on the nascent codes, or codes that shared similar meaning 
with other codes. This step was simultaneously a means of verifying the fit of the initial codes to the interview data as well as the beginning of the process for locating themes within the codes. The point of this phase was about assembling the codes into similarlythemed groups. It should be noted that this process was not linear. Rather, it took several iterations to compare the initial codes that were marked for each interview with initial themes that encompassed the entire data set. It was a process of going back and forth to check codes for their fit with the themes. If it was found that a certain code did not fit a particular theme, a new theme was created. At the end of this code-to-theme phase, all codes were assigned to one of the established themes. For example, interview data that was coded as "protection from the street" or "protection from the elements," as a reason for someone to stay at R2DT, was associated with a greater theme of "support".

After all codes were grouped into themes, it was necessary to reassess the themes themselves. This process was to see if the themes accurately described the codes that they were grouped with. If a certain theme had a meaning too similar to another, the two themes were condensed to create one theme. In these instances, codes were rechecked to make sure they would fit the newly-condensed theme. This was to assure that creating fewer themes was not detracting from the breadth of topics within the data.

When the final themes were established (Table 1), an ordinal process was used to organize the themes. Themes were compared with the original goal statements for the research. The goals for this research, again, were to identify the significance of the rest 
site for its users, how the space is contingent on a greater network of social services in Portland, and to assess how the social interactions produce the space.

Table 1. Final themes from data analysis.

\begin{tabular}{|c|c|c|c|}
\hline \multicolumn{4}{|c|}{ Final Code Book } \\
\hline Main Theme & \multicolumn{3}{|c|}{ Sub-Theme } \\
\hline \multirow{2}{*}{ Space of Support } & \multicolumn{2}{|c|}{ Protection and Security } & Stability \\
\hline & \multicolumn{2}{|c|}{ Accommodation } & Enabling \\
\hline Centrality of Site & Accessibility & Visibility & Mobility \\
\hline \multirow{2}{*}{$\begin{array}{l}\text { Socio-Spatial } \\
\text { Interactions }\end{array}$} & \multicolumn{2}{|c|}{ Responsibility } & Privilege \\
\hline & \multicolumn{2}{|c|}{ Cooperation } & (Dis)respect \\
\hline
\end{tabular}

Themes that directly related to these goal-statements were ranked "higher order" themes. Consequently, themes that did not directly relate to the research goals were ranked as "low order". Once higher-order themes were established, the data set was once again analyzed to determine that the interview data supported the high-order themes. This process involved going through the interview data to select extracts that originally supported the creation of those themes. This was simultaneously a final verification that the meaning of the interview data was accurately represented through the theme it was assigned with.

As a result of this analytic process, the three main themes of support, centrality, and of socio-spatial interactivity were selected as most representative of the research goals (see Appendix B for code percentage and frequency). While the method of thematic analysis as Braun et al. (2012) describe it was not followed to the exact detail, the central 
focus of identifying patterns across the data set for this method was closely followed. The resulting themes that were prominent across the data set will be detailed in the next section. 


\section{Chapter VI: Findings}

The first prominent theme established through the analysis is the notion of the rest site as a supportive space. This idea reiterates how the rest space plays a supporting role in the lives of homeless individuals. The second theme I cover is that of centrality. This takes on many different meanings and is critical for sustaining the rest site. The final theme I develop is that of the production of the rest site as a functional space. Here I suggest the result of the many social interactions that coincide to create the social space of the rest site produces, and reacts to, the organization of the physical space of the site. In other words, the social elements of living within this rest site affect how the space is used and how individuals' experiences were shaped by the space.

\section{Space of Support}

There are many roles that R2DT plays as an emergency shelter and rest space for the homeless. I identified four support functions the space achieves; a space of protection and security, a space of accommodation, a space of stability, and a space as enabler. While related, each function has a distinct role in servicing those using the rest space. Each of the four functions is described below in reference to the rest site as a space of support.

\section{Space of Protection}

In its essence, the rest site functions in a similar manner to that of a traditional homeless emergency shelter or mission. It provides those in need with a safe and undisturbed place to rest for an extended period of time. Yet, it differs from a traditional 
shelter in that the sleeping spaces are not equipped with beds or mattresses, but comprised of tents, tarps, and wooden pallets. Sleeping bags and blankets are provided for over-night sleepers, and the members generally have their own linens. In this sense, everyone staying at R2DT is protected from the elements of cold, windy, and rainy weather.

But the site is protective in a second sense. A number of individuals stated that the rest site protected them from other people on the street. Some, while sleeping openly on the street, feared being harassed or attacked by others also living on the street, or even passers-by. Others were harassed by the police or downtown concierges, who often forcibly relocate people from their spot of choice. The sentiment below from Scotty, a member, was expressed by more than one individual; "I feel safe here. There are no cops or houseless people messing with you. There aren't other houseless people trying to steal from you or beat you up." Another member, Kris, expressed the anxiety that living on the street induced, saying that “When I was on the street, I couldn't sleep at night. I could never get relaxed enough. I was too concerned about someone taking my stuff." The rest site is then protective for individuals by isolating them from open interaction on the street from others wishing to harm them, or to simply move them from particular spaces. This protection can assuage some of the stresses of living on the street.

The rest site is protective in a third sense. A few individuals mentioned that they felt more secure in R2DT than they were while staying in a shelter or mission. There was a staunch opinion from some that staying in particular missions felt similar to being 
institutionalized, in that they were constrained in their actions of daily living. Among the reasons for this was that some missions were unsafe places because of drug use and or resident-to-resident violence. Others felt that missions were unresponsive to their individual needs and that unnecessary programs were being forced upon the residents.

One member, who solely goes by "Dickweed," was particularly aggravated with the mission and shelter system in Portland. He openly questions this system by stating that Transition Projects (TPI) "has how many deaths and costs how much? And Right 2 Dream Too costs the taxpayers zero dollars...The conditions at missions are worse than prison. Grotesque. Dangerous. There are bed bugs, cockroaches. Diseases are all around.”

The rest site is multi-faceted in its supporting role therefore. While it not only meets a very basic need for shelter from the pernicious elements of weather, it also plays a broader role in securing individuals from harmful social interactions. Closely related to the notion of the site as a supportive space is a second function, that of accommodation.

\section{Space of Accommodation}

The rest site is accommodating to its residents in many senses. Given the diversity within the population staying at the site, there are various categories of needs. The rest site attempts to take these needs into consideration to make up for lapses in traditional emergency shelter provisions. One major factor in its accommodating capacity is that it is a place for individuals to turn when they truly have no place to go. While many people can rely on staying with friends or relatives, or are admitted to a mission, shelter, or other transitional housing accommodation, there are some who cannot always obtain this 
support. The rest site will take anyone they can accommodate, as long as they are not filled to capacity. Additionally, if an individual happens to leave in the middle of the night, members staying at the site will seek out people sleeping in the neighborhood to offer them the vacancy.

This broad acceptance is again unique when compared with traditional shelters and missions. For instance, many homeless shelters are based on a lottery system. While lottery systems do work differently, in essence, if an individual does not get their number called, they do not get a bed. This can be unnerving for many people, especially those who are new to living on the street. Beyond simply receiving a bed, missions and shelters maintain some criteria for being accepted. For example, individuals must show proof that they have been immunized for tuberculosis before they can be allowed in. Although this is a beneficial safeguard for all using these spaces, this does not always match the reality for those living on the street. Some people just do not have any medical documentation that they have had such immunization or have never been immunized. This is one means of accommodation specific to R2DT.

A second contrast with the accommodating capacities of the missions and shelters is that R2DT allows couples to stay together in a designated space within the rest site. Also of significance is that the site allows individuals of both sexes to use the space, although single females who are staying overnight sleep in a separate space. Many shelters and missions only host one sex, or separate the sexes by floor. This aspect of R2DT has been particularly beneficial in keeping together couples who would be 
separated while staying at separate shelter spaces. One member, Scotty, expressed his happiness in being able to stay with his wife in the site, stating:

This is the only place [in Portland] where couples don't get separated. If other places do happen to take in men and women both, they still separate you... we are always trying to put our heads together on how to accommodate people and couples with a shortage of space. We are trying to expand the couples section right now, as it only holds six couples.

Finally, the rest site allows individuals with guide dogs to accompany them. All of these accommodations taken together are rarely offered by missions or shelters, positioning R2DT to accept a wide range of individuals. The ability to make it into a shelter can be meaningful in itself. More benefits can be conferred to individuals while staying in this space, a sense of stability.

\section{Space of Stability}

Closely related to the rest site as a space of accommodation, yet distinctive in this usage, the site is a critical space for helping to stabilize an individual. Often when individuals arrive at R2DT, they have been living in a state of anxiety and flux. Some have been living on the street for extended periods of time, or have never been on the street before. Generally, then, when individuals arrive at R2DT, they are looking meet the immediate bodily need for sleep. The space helps to stabilize one's surroundings enough to get the needed rest to remain healthy.

Nearly every over-night sleeper interviewed mentioned sleep as a major reasoning for coming to the site. Getting any sleep, however, is a major concern for many homeless. 
Basir, an over-night sleeper at R2DT, underscored the desire for this, mentioning "I couldn't find a place to stay, so I came here. It was a place I could finally get rest and out of the rain. Most nights when I was on the street I wasn't actually sleeping."

Not only are homeless individuals daunted by the task of looking for a place to rest, they are also looking to satisfy other pressing needs. Beyond sleep, the rest site provides a second form of stability, granting members the ability to leave their personal belongings in a secure place so they may go about their routines without being tied down to everything they own. These affordances are extremely important for individuals when they are looking for housing accommodations or employment, accessing medical care, or even going to get a meal. As one member, Kris, asked, "How can they not recognize how hard it is to look for a job with a house on your back?"

To have a dedicated place to leave your belongings can be crucial in affording individuals increased mobility to go about their daily routine without having to worry about or be burdened with their belongings. Particularly as a member of R2DT, you have a dedicated space to leave your belongings. Overnighters, however, do not have this luxury during the middle of the day. Although this relieves many individuals of the aforementioned burdens of carrying all of your belongings, dedicated spaces for the homeless can also sanction a general content for the abeyance in transitioning out of this emergency rest site. 


\section{Space as Enabler}

The benefits to establishing a sense of place for homeless individuals is incredibly important. This can often be achieved through a stable living situation. For some staying at R2DT, however, the stability of having a more permanent place to stay has enabled the continuation of personal harmful habits or inactivity in the search for stable housing. This was a point of discontent, mostly from over-night sleepers, but it also came from members as well. These positions are not always apparent at first glance, and were brought-up during interviews. Perhaps the most outspoken on this issue was an overnight sleeper, Mark, who felt particularly members were taking advantage of R2DT's unusual situation as a private-public space. He suggests that:

The members seem to have their own thing going on. A good of portion are strung out. Weed permeates the place at night. It is the perfect place for people with drug problems because there is private space and you get food donations... I feel like many of the members are waiting for someone to give them some stuff. Some are out here because it didn't match up one month. Some are here for fun, it is a lifestyle.

It is difficult to determine what proportion of the population at R2DT conforms to the behaviors suggested above. While this position toward members primarily came from over-night sleepers, one member recognized this tension as well. When asked about his experience at R2DT, he mentioned that some members were "milking it" with regard to actively looking for stable housing. These concerns are important to mention because while the site is there to help meet the immediate need of a particularly disadvantaged population, there will always be downsides. It is necessary to look at these points of 
contention, which are easy for outsiders to notice, and could ultimately be distracting to the mission of R2DT.

As a supportive space, R2DT is able to extend multiple forms of assistance to the homeless population that other emergency homeless services in Portland cannot always offer. Its most basic function is the protection from life on the street. It offers more than protection though, by accommodating requests to not be separated from a spouse or to leave and come back to your personal belongings at the end of the day. Despite the features that are in place to support individuals through this transition, potentially adverse effects for all individuals cannot always be planned for.

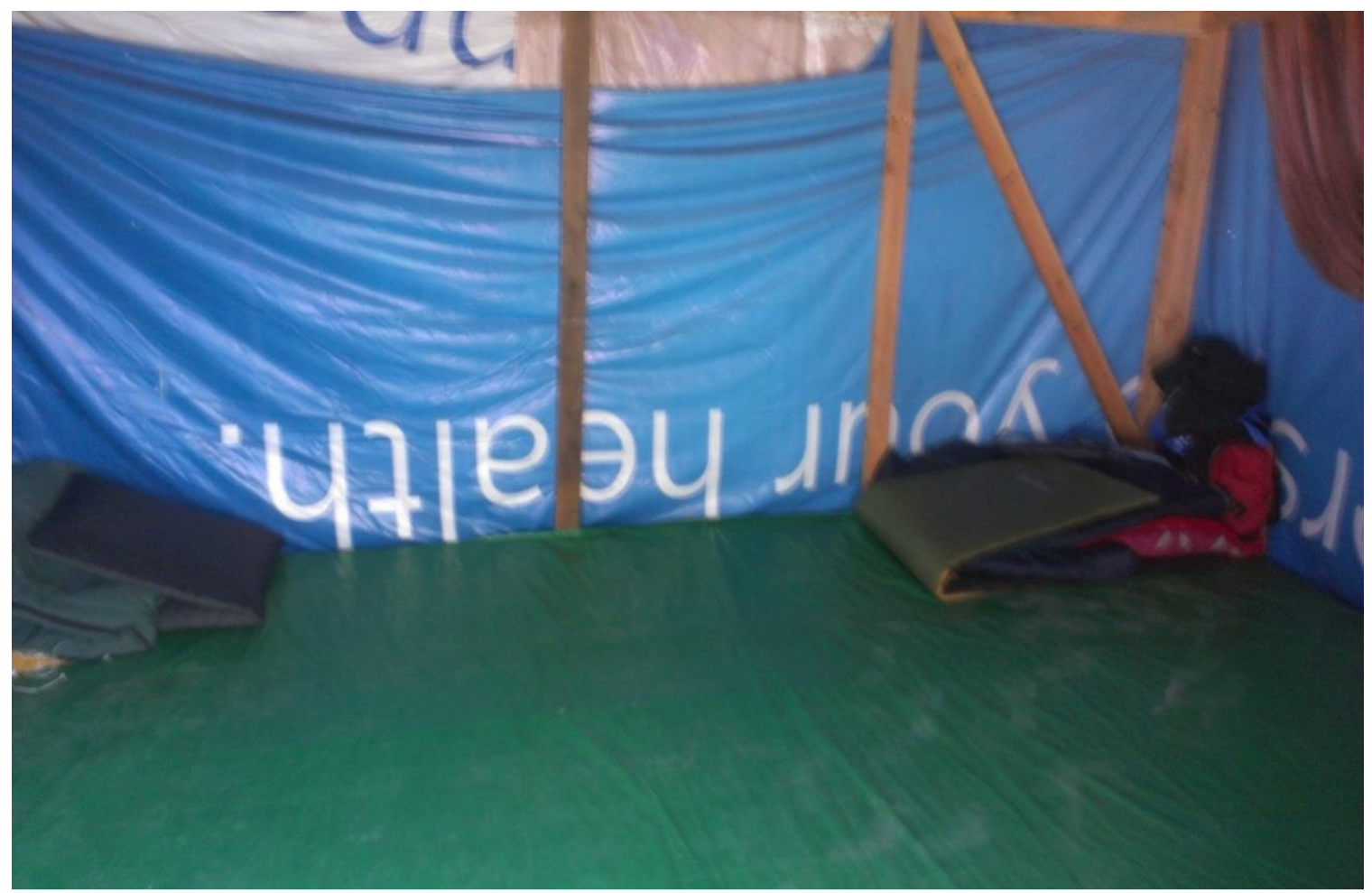

Figure 4. A typical sleeping space for overnighters. 


\section{Centrality of Site}

The second distinguished theme that emerged from this analysis concerns R2DT's situation within downtown Portland. Its location in the middle of Portland's downtown, neighboring the edge of the central business district, presents the site as a feature uncommon in traditional urban landscapes of North America. Further, its location within this particular area of downtown connects it with a greater network of similarly-aimed services for low-income individuals. Its location in many senses is central to its success.

Three subthemes describe the implications that the rest site's situation has for the individuals staying there. First is its proximity to a majority of the low-income services in downtown Portland. The second discusses the relative mobility this accessibility affords the individuals using this site. Finally, in more than one sense, its visibility plays a role in its sustainment. Understanding the importance of the site's centrality elucidates the importance of its particular location.

\section{Accessibility}

A major part of the accessibility afforded to individuals staying at R2DT is that a variety of services are in the immediate blocks surrounding the site. Indeed, the overwhelming reason individuals mentioned they were staying at R2DT was due to its proximity to social services in downtown. All but one individual interviewed stated that R2DT should be in downtown because it was close to services. The site's capacity as one provider of support is then augmented by the wider range of extant social services in its proximity. 
It is not simply that these services are located closely to one another, however. It is that there is accessibility to nearby resources that offer a holistic bundle of support services. They are varied within their servicing scope. For example, there are emergency shelters and missions that temporarily house individuals; there are meal handouts at several locations; laundry and showering facilities; clinics that offer medical assistance such as check-ups, mental health and substance recovery support; religious support; and job and skills training. For many, survival and the next step to stability is contingent upon their proximity to these resources.

It is clear that these are necessary spaces of support for the homeless staying at R2DT. Clarence, a member who is acutely aware of the benefits of clustering, stated that "if [the City] wants R2DT to move, then they need to move all the social services near the site it will be moved to". Consequently, if this were to happen, the homeless residing in downtown would have difficulty getting to a more geographically peripheral site. Anticipating the difficulty that getting out to resources not located in the central city would be, Scotty proclaimed that "If R2DT was out by the airport, Old Town people won't be able to get to it. Not everyone has a bus pass every day. I would rather sleep under the bridge than go out to $122^{\text {nd }}$ and Burnside for instance". Both of these statements speak to the particular geography of social service clustering in Portland.

\section{Mobility}

A dependent factor of an individual's accessibility to services relates to personal mobility. Being able to walk to every resource can often be the only option; having to 
depend on transportation is not always a reality. It is rare that the homeless have regular transportation and access to public transportation can also be problematic. For instance, if services were moved further out of downtown Portland, it cannot be assumed that these services would still be accessible solely because public transportation is available. Public transportation fares are a significant barrier for the impoverished. Roy, a member, emphasizes this situation, stating "We need a place that is easy to get to because many can't afford transportation to get all over. A lot of the homeless don't have the money to take the train or bus to get all over town to different services". Homeless individuals can be financially limited in their capacity to travel conveniently.

This immobility was apparent after analyzing the responses for the question: "Do you use any social services other than R2DT in downtown? How often? How do you get to these services"? When asked what services were used by each individual, thirteen distinct social services were mentioned in their responses (Table 2). Many services were mentioned multiple times. And for some particularly frequented services, almost all of the interviewees had mentioned them. In total, eleven of the thirteen services mentioned are within one mile of R2DT. Seven of the services are within one-quarter mile. All services were then mapped in proximity to R2DT (Figure 5). 
Table 2. Social Services used by R2DT Sleepers.

\begin{tabular}{|l|l|l|l|l|}
\hline Service Name & Address & City & State & Zip \\
\hline Transition Projects Inc. (TPI) & 665 Northwest Hoyt Street & Portland & OR & 97209 \\
\hline Union Gospel Mission (UGM) & 3 NW Third Avenue & Portland & OR & 97209 \\
\hline Central City Concern Clinic & 727 West Burnside Street & Portland & OR & 97209 \\
\hline Rose Haven & 627 NW 18th Avenue & Portland & OR & 97209 \\
\hline $\begin{array}{l}\text { Salvation Army Female } \\
\text { Emergency Shelter (SAFES) }\end{array}$ & 30 SW 2nd Avenue & Portland & OR & 97204 \\
\hline Portland Rescue Mission & 111 W Burnside Street & Portland & OR & 97209 \\
\hline $\begin{array}{l}\text { Saint André Bessette Catholic } \\
\text { Church (Red Doors) }\end{array}$ & 601 W Burnside Street & Portland & OR & 97209 \\
\hline $\begin{array}{l}\text { Oregon Department of Human } \\
\text { Services }\end{array}$ & 3975 SE Powell Blvd & Portland & OR & 97202 \\
\hline $\begin{array}{l}\text { Oregon Department of Human } \\
\text { Services (New Market) }\end{array}$ & 50 SW 2nd Avenue & Portland & OR & 97204 \\
\hline Blanchet House & 310 NW Glisan Street & Portland & OR & 97209 \\
\hline $\begin{array}{l}\text { St. Francis of Assisi Catholic } \\
\text { Church }\end{array}$ & 1131 SE Oak Street & Portland & OR & 97214 \\
\hline $\begin{array}{l}\text { Multnomah County Aging and } \\
\text { Disability Services }\end{array}$ & 421 SW Oak Street & Portland & OR & 97204 \\
\hline Portland Social Security Office & 1538 SW Yamhill Street & Portland & OR & 97205 \\
\hline
\end{tabular}

A service area buffer was applied to ensure that the distances from R2DT were incorporated into the infrastructural network of the built environment, so as to include the impedance of streets, buildings, and the Willamette River. The buffer distances were chosen to coincide with standard walking distance measures of one-quarter mile, one half-mile, and one mile ${ }^{7}$. With the network impedances accounted for, there is a more accurate indication of the distance from R2DT to other services throughout the city that are being used by R2DT sleepers. The results of this analysis show that R2DT is quite

\footnotetext{
${ }^{7}$ The measurement of quarter-mile, half-mile, and one mile is used in comparison to the popular application of Walk Score. Walk Score is an application that helps users to find certain amenities within a particular distance from a specific point on Earth. Walk Score's methodology is based on the same measurements as I have used: quarter-mile, half-mile, and one mile. The same walking standards apply from my methodology to theirs: one quarter-mile is about 5 minutes, one half-mile is 10 minutes, and one mile is 20 minutes.
} 
centrally placed within this cluster of services, making extremely accessible to its users the breadth of services located in this neighborhood.

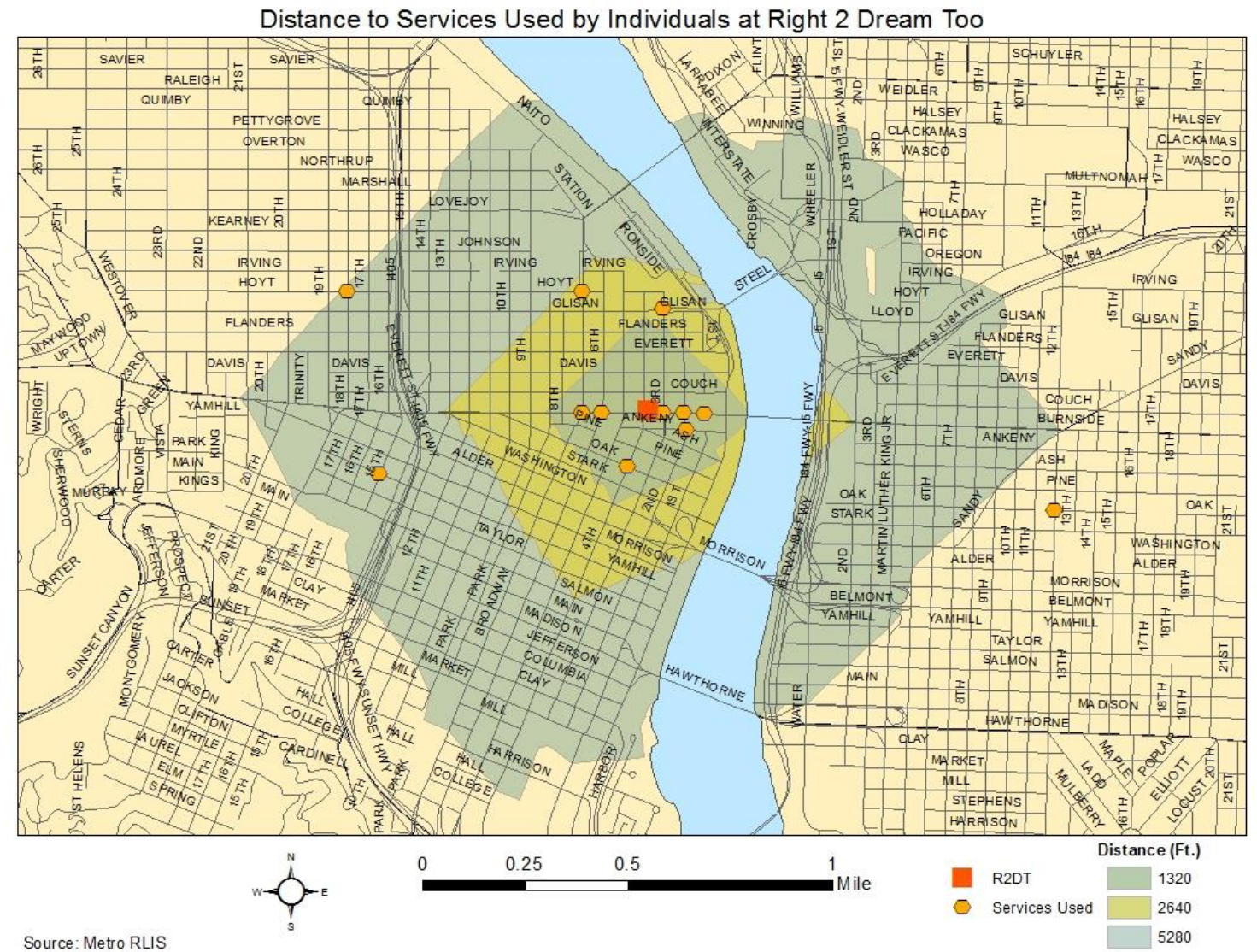

Figure 5. Social services used by those staying at R2DT.

\section{Visibility}

A third aspect of the rest site's central location is its high visibility within the downtown landscape. West Burnside Street, the street in which it is located, is welltraveled by pedestrians and as well as by automobile. The infrastructure of the rest site is itself eye-catching, but juxtaposed against the Chinatown Gate, it is highlighted even more. On such a well-traveled path, it is not hard to find; especially as it is in the center 
of the Old Town service cluster. Kirsten, a member, reiterates the ease in which she found R2DT. When asked about why she chose to stay at R2DT she responded, "I was just walking by one day and stopped in to ask about what it was. A few days later I started staying there. There is visibility where it is located now, and that's how I found it". Thus it is its approachability that makes it a vital resource for homeless individuals.

In this sense it is an information center, or node, for the homeless. For, the R2DT's members make up a large support network containing a wealth of information about surviving on the street. Often the members are able to assist people in finding where they can go to meet different needs. This kind of street-sense information is an invaluable resource for those who have not had to face the uncertainty of living on the street before. The rest site is, then, not only a resource for those who use the space, but for people who are in need of direction for navigating unfamiliar circumstances.

Equally important concerning the visibility of the rest site is that it reminds us that homelessness continues to be an issue in Portland. Its physical infrastructure, literally the doors that bound the place together, projects statements of hope for those individuals using the space. Painted on these doors are calls for justice regarding issues such as social equality through affordable housing. It is the literal occupation of this space that continues to draw attention to the severity of the issue and promote their calls for equal housing opportunity. The occupation of such central space has been critical in fostering not only social, but political support as well. 
Due to the rest site's situation in downtown among social services, R2DT has defined itself as a crucial resource for homeless individuals. As a place to sleep, or get advice on where to go for other resources, it plays a significant role in the provisioning of homeless services in Portland. Its situation within the city has connected it with broadbased and densely clustered service network that meets a wide range of needs for lowincome individuals. Its occupation of this site has legitimated its presence as a reliable service.

\section{Socio-Spatial Formations}

The final theme eminent in the analysis relates to the interactions between individuals and the rest space itself. Certainly, the sheer number of people in the space every day complicates its functionality. But it is not only the individuals in the space that creates complexity, but is also the space itself that complicates these social processes. In other words, the rest site is subject to the dynamics of social processes, and in turn, these social processes shape the space itself (Soja 1980). This is not to say that the site functions without a relatively defined order. Rather, the interactions between the users of this space continually manifest themselves within the organization of the space itself. Therefore, it is important to look at these socio-spatial dynamics to contextualize how the rest space has been shaped.

The experiences of individuals at the site are varied. Many individuals mentioned that staying at the rest site provided a sense of responsibility in their lives that they had not previously had on the street. This sense of responsibility came in many forms. For 
instance, there are a variety of jobs that members enact daily and weekly to ensure that the space runs efficiently. Tasks range from front desk check-in and information to security, shared-tent washing and cleaning, and cooking for the group. Looking after the space and the people within it established a sense of value for some.

Several people mentioned having positive experiences with others there as well. Some mentioned a friendly or familial atmosphere. For example, Trisha, a member, said that "Everybody is friendly and nice. They will split their money with you like a family". Another member, Roy said that "Once we found out about how [the site] operates, we liked it even more. There are good people here. We consider ourselves family". But community is not always easily established, however. For some it took time to acclimate to a new lifestyle. For instance, Amber, a member who had not previously been homeless said that prior to staying at R2DT, "I had always been housed and had misconceptions about the houseless. R2DT showed me community...there is a sense of responsibility here. That's why people have been successful at R2DT". The rest site was a positive experience for some as they became a more constant part of this community.

Perhaps from shared working responsibilities, individuals also mentioned that sharing such a small space with so many people enforced a sense of cooperation. Kris, a member, reflected this stating that "you learn not to be self-absorbed. Some [sleepers] have disabilities or strong personalities, so you need to learn to be patient with the others 
using the space too". For some who did not feel it was an amiable situation, there was a notable culture of tolerance and respect toward others in the community.

Certainly positive and or communal feelings were expressed by some individuals and not hard to detect within the rest site. There were others, however, who expressed negative opinions of the interactions between individuals within the space. These negative statements were most marked when speaking with over-night sleepers. For example, Mark, an overnighter, expressed discontent with his experiences at the rest site, stating that "The homeless members in charge are going after the homeless overnighters. It can be degrading. It is like they have never had a job with responsibility over people. They certainly have never had a class in etiquette".

A feeling of disrespect was felt by others. Another overnighter, Lindell, even suggested that members have extra privilege, stating “They don't keep tabs on the members. Some come in drunk; overnighters can't. There is a hierarchy here. So some members get to do things that overnighters can't. If you have a bad day here, it's because others make it that way for you". Leslie, also an overnighter, felt similarly about the member-overnighter interactions, asserting that "Some [members] think they are better than everyone else and that they should be given special treatment". Touching on many of these points, Israel saw a more balanced social situation, saying that "Most of the members are good. They are friendly to you on some occasions. A few others are judgmental though. Some go on a power trip sometimes. The place could be run more 
efficiently". While it is clear that some overnighters did not have positive experiences at the rest site, disrespect was not indicative of all overnighters experiences.

Negative social interactions between members and overnighters were not as pronounced when talking with members. In fact, members had no unfavorable comments about overnighters. This may be due to the ephemeral nature of overnight sleeping at the rest site. Members can see hundreds of individuals come through the site and perhaps do not have interactions with each of them. Additionally, for members who have resided at the site longer-term, recalling negative experiences may have been less significant compared with the negative experiences of overnighters who may have been there for only one or two days. Whatever the reasons for this, there remains divisiveness of opinions regarding social relations with the rest site.

Part of this divergence may be because of the spatial arrangement of the rest site itself. All overnight members sleep in very close proximity to one another, under semi open-air tarps, whereas the members have personal tents that can be closed off. Formerly, however, the members slept in their own distinct area which was blocked off to the overnighters (Figure 6). There were particular spaces in which overnighters were not allowed, as well as particular times in which they could not be awake and moving around through the site. The makeup of the rest site has changed since interviews were conducted. 


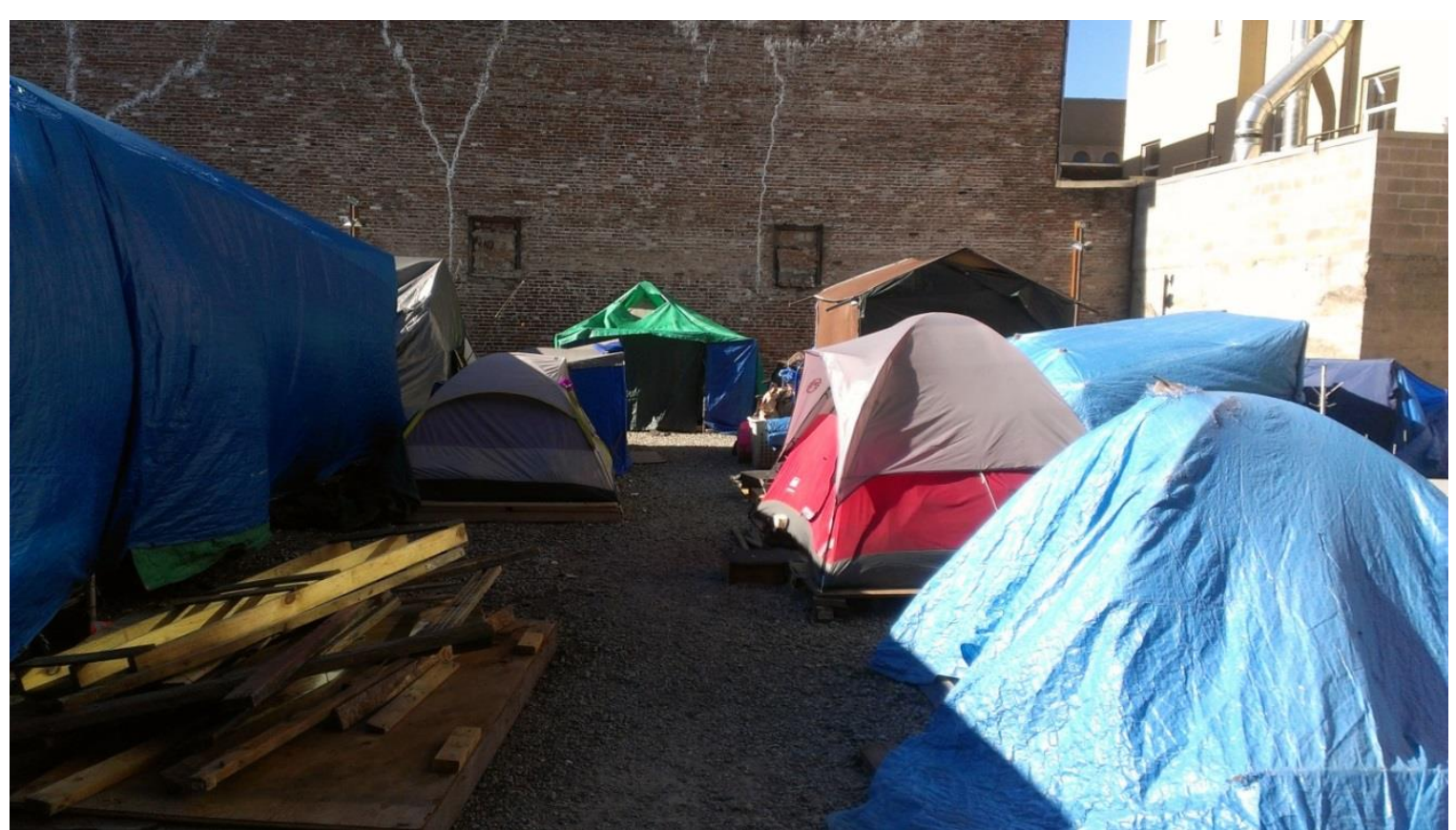

Figure 6. Members' individual tents, behind the main overnighter tent (left), in the back half of the rest site.

This spatial occlusion did not go unnoticed by the overnighters. Mark, an overnight sleeper who spent several weeks there, mentioned that he was not allowed to be in the designated smoking corner of the rest site to smoke cigarettes. He stated that "when you are forced to go straight to your bed at 9:00pm, [the members] all get to stay up and smoke...it's party time". Another overnighter, Lindell, had a similar experience when he was asked not smoke inside the rest site, although he was in the designated smoking corner $^{8}$. In some instances, overnighters felt excluded from particular spaces, feeling regulated in their use of the rest space.

\footnotetext{
${ }^{8}$ The author was also put in a precarious position while interviewing an overnighter. Although the author was given clearance to conduct the interview in the empty corner, a member approached and questioned the interviewee as to why he was smoking there, much less being in that space.
} 


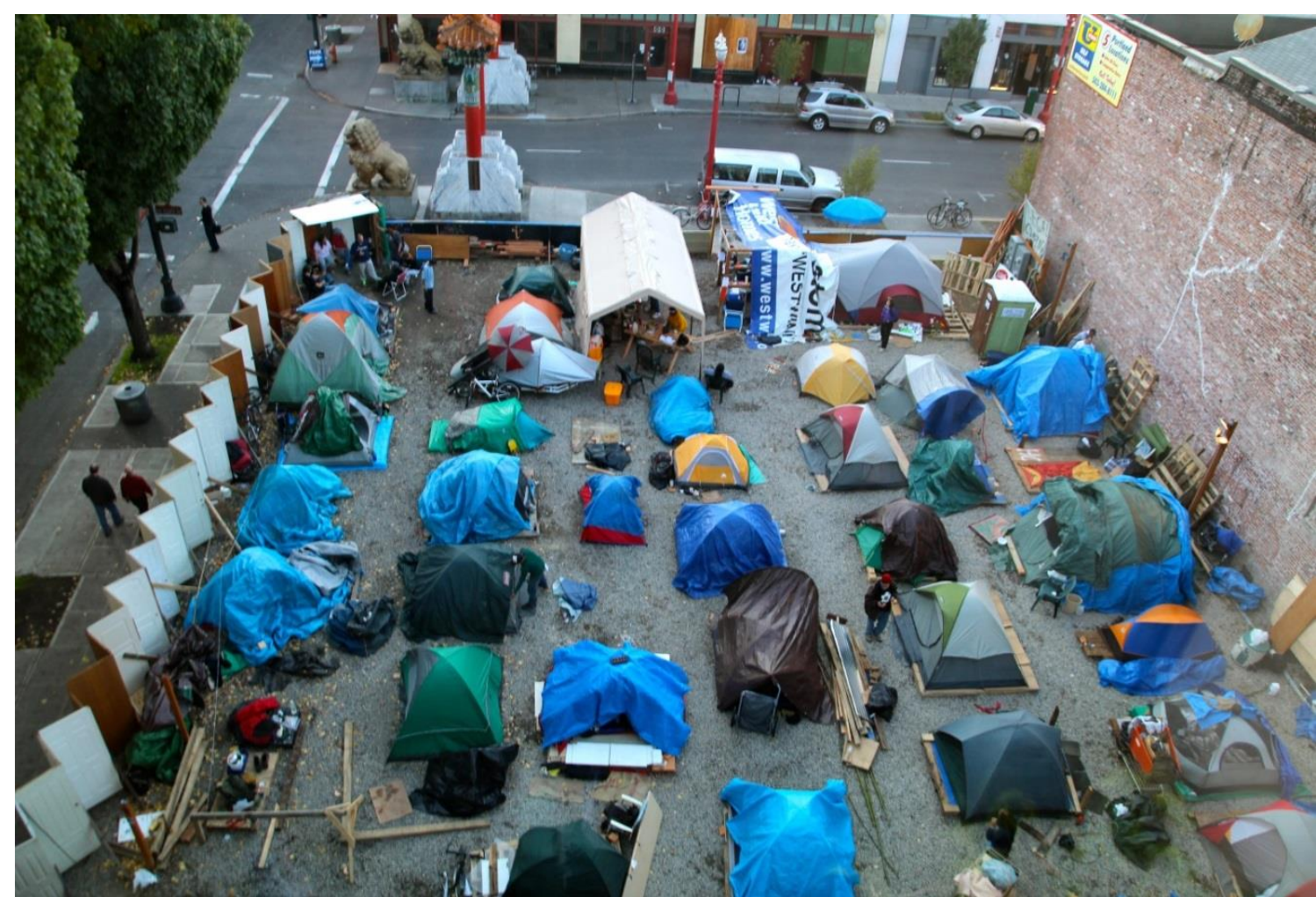

Figure 7. Original organization of the site (Winter 2012) where all people slept in one open area. Source: Bayer, I (2012). 


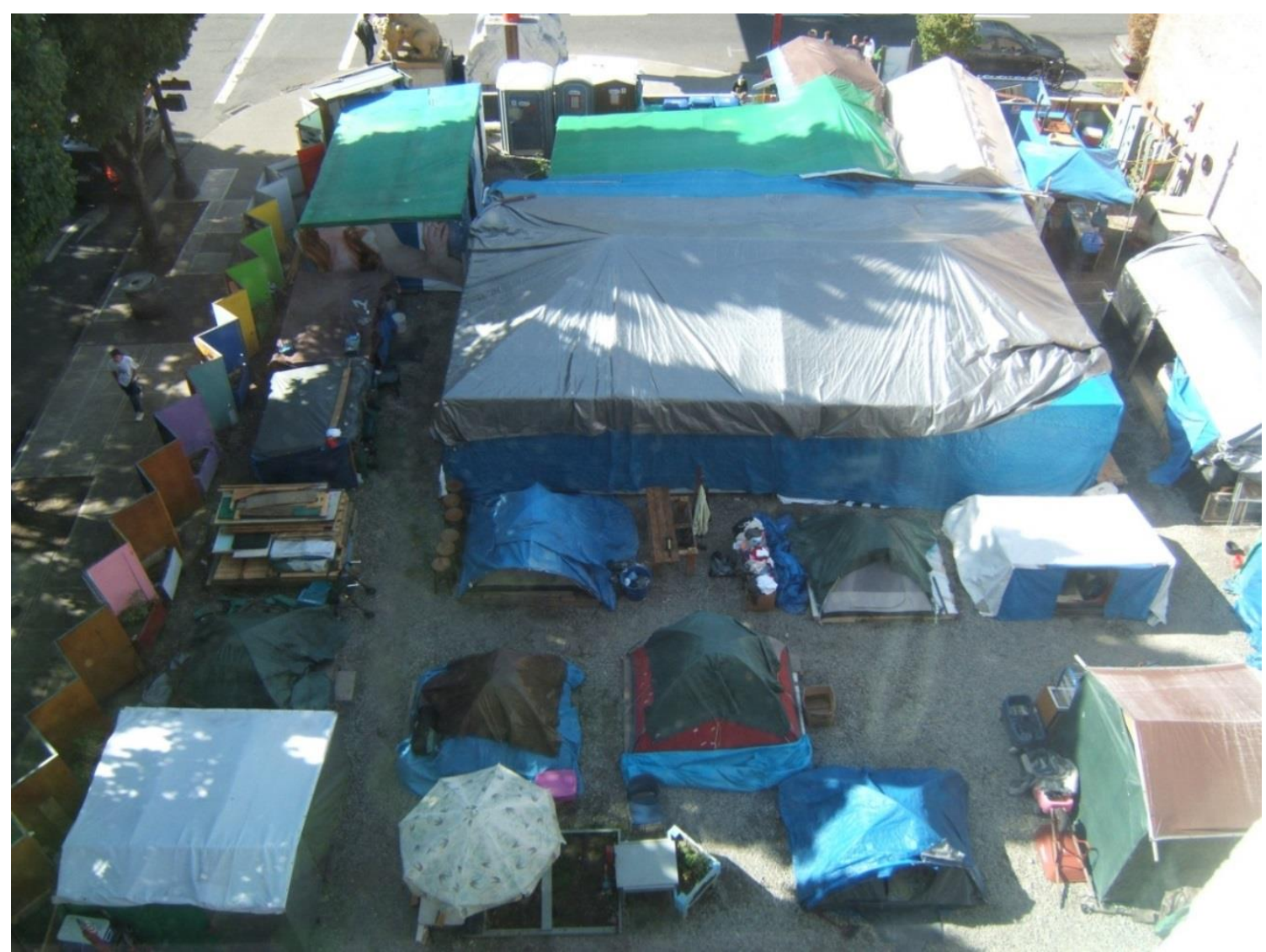

Figure 8. Current organization of the rest site (October 2014). The large middle tent is the main overnighter tent. Smaller overnighter tents are placed near the entrance of the site, shown at the top of this photo.

The unusual demarcation of "proper" space for overnighters was not mentioned much more than by these few people. There were more adverse remarks about the space itself, however. For example, many people mentioned that the space in general was too small. Overnight sleepers especially felt cramped together. It was often stated that simply a larger space was needed to fit all sleepers comfortably.

This nearly unified response came mostly when asked where the site should relocate to. Others mentioned the relatively unhygienic climate of the space, due to the 
lack of running water for bathing and cleaning. Indeed, Tina, a nurse who was quite melancholy when I met her was candid about the conditions, mentioning that "Being dirty is not a good feeling. Not being able to shower as often as you may want is hard". Others mentioned that the site was too noisy at night due to the surrounding entertainment sites throughout the immediate neighborhood. It was apparent to many of the individuals staying at R2DT that they were spatially constricted.

Despite these particularly inharmonious interactions, this does not suggest that the individuals in this space are incapable of operating a successful rest site. As stated previously, the site continues as a safer space for individuals to sleep day after day. Instead, these comments are a reflection of the various backgrounds and personalities that are forced to interact due to unfortunate circumstances. The outcomes of these interactions sometimes manifest themselves verbally. This may add dissonance among others within the site. But these interactions also manifest themselves spatially; suggesting that not all of these individuals are housed comfortably.

\section{Discussion}

The rest site is an intricately-produced space. It was established as a transitional housing accommodation to meet the dearth of emergency shelter spaces for unsheltered individuals to sleep safely. As suggested, it meets this fundamental human want, offering a sense of protection, stability, and is accommodating to the various needs of this population. It is however, a space that is regulated, primarily by those staying in the 
space. This has had a permissive effect for some to simply "maintain" in this space. In other words, for these individuals, it is not being used as transitional housing.

Despite this minority perspective toward the purpose of the rest site, it is clear there is widespread dependence on its proximity to numerous social services. The overwhelming majority of people interviewed stated this was the main reason they were staying at R2DT. People were less set on this particular site as the only appropriate place to run R2DT. It other words, it was the access to these services that was preeminent in their decision to stay there. This is an important distinction to make about the site's highly visible and public location in downtown Portland. Therefore, it can be argued that the rest space does not necessarily need to be located on this particular lot, in this downtown location. It does suggest, however, that the rest space needs to be within a significant service cluster to augment its supportive capacity. The only dense cluster of supportive services in Portland is found in this particular neighborhood.

As a highly visible resource itself in downtown, the space provides critical support for individuals in need, regardless of whether they are staying at the site or not. As a highly interactive space, it is organized quite efficiently. Members staying in the space for longer periods of time suggest there are benefits of communal living for them such as a sense of responsibility and collaboration.

For those individuals with less attachment to the space, temporally or socially, their interactions within the space were less useful in their struggles to obtain stability. Some felt highly controlled by others in the site citing a sense of powerlessness over their own actions while staying at the site. There seemed to be a hierarchical relationship 
between the members and overnighters. Perhaps this is due to the amount of time the members have resided in the spaces relative to the overnighters.

What is more, the space itself seems to constrict and hinder particularly the overnighters' experiences while staying there. Surely the space is not large enough to sleep 60-80 people as comfortably as everyone there would like. Cramped living quarters, specifically for overnighters had some effect on their willingness to stay at the site. More significantly, some overnighters were also excluded from accessing particular areas of the rest site. Thus they were occluded from spaces within the rest site that are ostensibly for the entire community residing there. This is best represented by the differentiation of sleeping areas, where members have individual tents in the rear of the space, and overnighters sleep tightly together in one bigger tent. Despite these inharmonious occurrences between members and overnighters, overnight sleepers still recognized the value of having some shelter and community that ultimately looks out for one another. 


\section{Chapter VII: Conclusion}

In the previous chapters I have argued that cities are critical spaces for producing the global economy. As globalization processes unfold, the once-held responsibility of national governments has slowly devolved to the local or urban scale, as well as the global scale. With increasing political autonomy, urban governments have subsumed responsibility for new spheres of political, economic, and social policy implementation. Increasing independence from the sovereignty of the national-state, however, has affected cities' ability to maintain necessary social welfare programs, and has resulted in the greater socio-spatial inequality within cities.

Global economic changes over the last forty years have contributed to this increase in inequality. As the financial recession hit in the early 1970 s, cities were experiencing deindustrialization, rising unemployment and witnessing the hollowing-out of the urban core. In the midst of this recession, came the rise of neoliberal policies. These policies advocated for the deregulation of government in the market and the eradication of public spending for social programs. Among the hardest hit was housing assistance through declining HUD budgets. This effectively stopped the construction of subsidized affordable housing and is a major reason homeless numbers have continued to increase nation-wide since the early 1980 s.

In parallel with the rise of neoliberal policies, urban governments saw a shift in development approaches, competing for private investments to promote growth. The consequences of this shift can be seen in the diminishing support for cities' most vulnerable populations. Many social programs for low-income populations have been cut 
or eroded completely. In many cities today social support measures are facing increasingly uncertain futures.

The economic reorganization of urban development approaches has markedly affected social services that support the homeless. There remains a large-scale shortage in affordable housing and emergency shelter services in cities across the U.S. The result is an increase in unsheltered homeless populations, of which cities like Los Angeles, San Francisco, Seattle, and Portland are all seeing. What is more, the increase in punitive urban policies that restrict the homeless from living and being in public spaces has intensified what was already a significant issue for the homeless. Collectively, it has become increasingly harder for the homeless to survive in urban areas.

The geographies of homelessness have shown that urban homelessness has been, and continues to be, a significant factor in the rise of homeless numbers. This is intricately tied into the economic processes of urbanization. But it is also due to the larger concentration of low-income support services available in the inner cities. Consequently, there are often particular sections of the cities where services are concentrated. This has the tendency to pull individuals in dire need of these services to these particular areas of cities. There is an almost cyclical relationship with the homeless and these services. In Portland, this area has consistently been the Old Town neighborhood for decades, where homelessness is most visible in the city. Consequently, there is a multitude of services in Old Town that serve the impoverished. 
Despite the fact that these services have been operating in this area for decades, Portland's homeless population continues to rise. This indicates that these services alone cannot accommodate and thus reduce the number of homeless individuals in the city. This is compounded by the fact that tens of thousands of affordable housing units are not available for low-income renters. It is equally problematic that there are not enough emergency shelter beds to meet the needs of this population. These issues and others establish a quite complex situation to overcome for the homeless in Portland.

To be sure, no one solution will completely mitigate homelessness. Rather, multifaceted support is needed to stabilize the disparate situations of homeless individuals. Providing shelter is one of these basic needs. But when there are huge shortages in shelter availability, as well as a lack of financial support to increase the construction of shelter space, organic modes of survival become imminent for homeless individuals. This often results in uncommon ways of living, such as squatting, sleeping in public, and creating ad hoc shelters or encampments. These alternative modes of living are a reaction to a weakened support system, and should be critically examined in this context.

R2DT is one such reaction to this weakened support system. As a tented rest site in the middle of downtown Portland, it is not a traditional social service. Yet it has established itself as a reliable service for the homeless, day in and day out, for several years. In part this is due to its geographic location. Not only is it centrally located within the city, it is at the nexus of a wider system of support for the homeless. This is overwhelmingly why individuals have chosen to stay there. 
Individuals have also chosen to stay there because they felt it was a safer alternative to life on the street. As a space of security, it affords people the ability to sleep in some shelter, and to be surrounded by a larger community of individuals who understand the pressing issues of living in this environment. It is thus accommodating for people who are in need of very basic resources. It is a transitory space, in that many people move in and out in regular flows. This of course, is a situation rife for social and spatial conflict. And there have been both; which has figuratively and literally shaped the rest space that exists there today.

As a homeless rest site that sits on privately-owned property, it is intricately tied into the larger processes of land use economics that fuels urban development. But it is precisely because of this that the rest site has flourished. As a highly centralized and visible homeless resource in downtown Portland, it has garnered the recognition of municipal leaders that this particular self-organized model is helping meet the city's need for emergency shelter space. And while its fate at this specific site is ultimately tied into the logistics of the property market, it has served as a visual reminder that there is an extant homeless population that remains underserved.

The spatiality of the rest site has thus been instrumental in establishing R2DT as a significant contribution to Portland's service network. The success of this particular rest site is socially and geographically contingent, however. Because of this, questions still remain which afford opportunities for further research. For instance, how could this site be successfully rescaled within Portland? How can we explain smaller establishments of homeless camps in other parts of the city that are not near service clusters? Could the site 
be replicated in other cities? And finally, what are the issues facing the homeless in other cities in the U.S. and world-wide? Much can still be learned about the proliferation of homeless self-organized rest spaces.

The utility of this research is, of course, supplemental to these questions. It presents a series of complex issues that when unpacked, illustrate the capacity for individuals to reduce unequal access to necessary services for their own survival. R2DT is calling for the right to produce urban space that affords shelter for those individuals who are left unsheltered. Understanding the spatiality of these inequalities is therefore an important start for transformation. This contextualization is necessary or we run the risk of misinterpreting social inequalities as aspatial. Homelessness is not geographically vacuous. Rather, it is continually shaped and reorganized by the actions of innumerable social actors at different scales. 


\section{References}

Abbott, C. 2001. Greater Portland: Urban Life and Landscape in the Pacific Northwest Philadelphia: University of Pennsylvania Press.

Bayer, I. (Photographer). 2012 . Overhead view of Right 2 Dream Too [Photograph]. Retrieved 10 December 2014, from: http://news.streetroots.org/2012/01/05/making-dream-reality-right-2-dream-too-ssuccess-flies-face-skeptics

Beckett, K. and S. Herbert. 2010. Banished: The new social control in urban America. Oxford: Oxford University Press.

Bernstein, M. 2014. Portland Police Chief Mike Reese sounds alarm on downtown homelessness, introduces 'Prosper Portland' initiative. Oregonian, 4 February. Available http://www.oregonlive.com/portland/index.ssf/2014/02/portland_police_chief_mi ke_ree_15.html (last accessed 5 March, 2014).

Bockman, J. 2013. Neoliberalism. Contexts 12(3): 14-16.

Braun, V. and V. Clarke. 2012. Thematic analysis. In APA research methods in psychology: Volume 2, research designs, ed. H. Cooper, 57-71. Washington DC: American Psychological Association.

Brenner, N. 2011. Cities for people, not for profit: Critical urban theory and the right to the city. London: Routledge.

--- 2006. Global cities, 'glocal' states: Global city formation and state territorial restructuring in contemporary Europe. In The global cities reader, ed., N. Brenner and R. Keil, 259-66. New York: Routledge.

Brenner, N., B. Jessop, M. Jones and G. Macleod. 2003. Introduction: State space in question. In State/Space, ed. N. Brenner, B. Jessop, M. Jones and G. Macleod, 126. Malden, MA: Blackwell Publishing.

Brenner, N. and N. Theodore. 2002. Cities and the geographies of "actually existing neoliberalism". Antipode 34(3): 349-379.

BRC (Burnside Neighborhood Committee). 1972. Position statement of the Burnside Neighborhood Committee on the downtown plan. Available at http://digital.lib.pdx.edu/oscdl/files/downtown_plan/pdx004s0031.pdf (Last accessed 23 October 2014).

CCC (Central City Concern). 2014. History. Available at http://www.centralcityconcern.org/ccc/ 
Citizens Commission on Homelessness. 2004. Home again: A 10-year plan to end homelessness in Portland and Multnomah County. Available at http://www.portlandonline.com/shared/cfm/image.cfm?id=103921 (last accessed 9 December 2014).

City of Portland and Multnomah County 2013. A Home for Everyone: A United Community Plan to End Homelessness for Portland/Multnomah County. City of Portland Housing Bureau. Available at https://www.portlandoregon.gov/phb/article/443314 (last accessed 8 March 2014).

Cloke, P., P. Milbourne and R. Widdowfield. 2001. The geographies of homelessness in rural England. Regional Studies. 35(1): 23-37.

Cloke, P. 2000. "The hidden and emerging spaces of rural homelessness". Environment and Planning A 32(1): p. 77-90.

Cox, Wendell. 2014. Special Report: 2013 Metropolitan Area Population Estimates. Available at http://www.newgeography.com/content/004240-special-report-2013metropolitan-area-population-estimates (last accessed September 9 2014).

Cresswell, T. 2004. Place: A short introduction. Oxford, UK: Blackwell.

Dear, M. and J. Wolch. 1987. Landscapes of Despair. Princeton, N.J., Princeton University Press.

DeVerteuil, G., J. May, and J. von Mahs. 2009. Complexity not collapse: Recasting the geographies of homelessness in a 'punitive' age. Progress in Human Geography 33(5): 646-666.

Distilled Publishing. 2007. West Burnside: Logging the Skid Row. Available at http://distilledpublishing.blogspot.com/2007/06/west-burnside-logging-and-skidrow.html (last accessed 11 November 2014).

Emmons, S. 2013. "Solving Homelessness" from Oliver Lecture held at First Congregational United Church of Christ, Portland, Oregon. 17 November, 2013. Available at http://www.nwpilotproject.org/advocacy/solving-homelessness.php (last accessed 3 March 2014).

Flanagin, J. 2014. What Is The World's Most Livable City? New York Times, 4 August. Available at http://op-talk.blogs.nytimes.com/2014/08/04/what-is-the-worldsmost-livablecity $/$ ?module $=$ Search\&mabReward $=$ relbias $\% 3 \mathrm{As} \% 2 \mathrm{C}\{\% 221 \% 22 \% 3 \mathrm{~A} \% 22 \mathrm{RI} \% 3$ A $5 \% 22\}$ (last accessed 31 October 2014). 
Friedmann, J. and G. Wolff. 1982. World city formation: An agenda for research and action. International Journal of Urban and Regional Research 6(3): 309-344.

Hall, T. and H. Barrett. 2012. Urban Geography, $4^{\text {th }}$ Edition. New York: Routledge.

Harvey, D. 2012. Rebel cities. London: Verso.

--- 2008. Right to the city. New Left Review 53: 23-40.

--- 2005. A brief history of neoliberalism. New York, NY: Oxford Press.

--- 1989. From managerialism to entrepreneurialism: the transformation in urban governance in late capitalism. Geografiska Annaler. Series B, Human Geography 71(1): 3-17.

Herbert, S. and K. Beckett. 2010. 'This is home for us': Questioning banishment from the ground up. Social \& Cultural Geography 11(3): 231-245.

Hunter, J., P. Linden-Retek, S. Shebaya, and S. Halpert. 2014. Welcome home: The rise of tent cities in the United States. Available at:

http://nlchp.org/documents/WelcomeHome_TentCities (Last accessed 29 June 2014).

Jessop, B. 2002. Liberalism, neoliberalism, and urban governance: A state-theoretical perspective. Antipode 34(3): 452-72.

Jurjevich, J. and G. Schrock. 2012. Is Portland Really the Place Where Young People Go to Retire? Migration Patterns of Portland's Young and College-Educated, 19802010. Metropolitan Knowledge Network, Institute of Portland Metropolitan Studies and the Population Research Center. Available at http://mkn.research.pdx.edu/wpcontent/uploads/2012/09/JurjevichSchrockMigrationReport1.pdf (last accessed 25 October 2014).

Keil, R. 2003. Globalization makes states: Perspectives on local governance in the age of the world city. In State/Space: A reader, ed. N. Brenner, B. Jessop, M. Jones and G. Macleod, 278-95. Malden, MA: Blackwell Publishing.

--- 2002. "Common-sense" neoliberalism: Progressive conservative urbanism in Toronto, Canada. Antipode 34(3): 578-601.

Knox, P. and L. McCarthy. 2005. Urbanization: An introduction to urban geography. New Jersey: Pearson Prentice Hall. 
Korn, P. 2012. Right 2 Dream Too stares down threat. Portland Tribune, 20 December: n.p. Available at http://portlandtribune.com/pt/9-news/125230-right-2-dream-toostares-down-threat (last accessed 12 March 2013.)

Lee, B. and T. Price-Spratlen. 2004. The geography of homelessness in American communities: Concentration or dispersion? City \& Community 3(1): 3-27.

Lefebvre, H. 2009. State, space, world: Selected Essays, ed. N. Brenner and S. Elden. Minneapolis, MN: University of Minnesota Press.

--- 1996. The right to the city. In Writings on cities, ed. E. Kofman and E. Lebas, 63-181. Oxford, UK: Blackwell Publishing.

Malanga, S. 2012. Bushwhacked by Obama: The ironic fate of the Community Development Block Grant program. City Journal, Summer 2012.

Marcuse, P. 2014. Reading right to the city. City: Analysis of urban trend, culture, theory, policy, action 18(1): 4-9.

McMichael, P. 2012. Development and social change: A global perspective. London: Sage.

Miller, C. 2014. Will Portland Always Be a Retirement Community for the Young? New York Times, 16 September. Available at http://www.nytimes.com/2014/09/21/magazine/will-portland-always-be-aretirement-community-for-the-young.html?_r=0 (last accessed 25 October 2014).

Mitchell, D. 2003. Right to the city. New York, NY: Guildford Press.

--- 1997. The annihilation of space by law: the roots and implications of anti-homeless laws in the United States. Antipode 29(3): 303-335.

Mitchell, D. and N. Heynen. 2009. The geography of survival and the right to the city: Speculations on surveillance, legal innovation, and the criminalization of intervention. Urban Geography 30(6): 611-632.

NAEH (National Alliance to End Homelessness). 2014. The State of Homelessness in America 2014. Available at http://b.3cdn.net/naeh/d1b106237807ab260f_qam6ydz02.pdf (last accessed 11 September 2014).

National Coalition for the Homeless. 2010. Tent Cities in America: A Pacific Coast Report. Available at: http://www.nationalhomeless.org/publications/Tent\%20Cities\%20Report\%20FIN AL\%203-10-10.pdf (Last accessed 29 June, 2014). 
Office of City Auditor. 2013. Urban Services Policy and Resolution A: Core City services not articulated; 30-year-old commitments obsolete. City of Portland: Audit Services Division.

ORS (Oregon Revised Statute). 2011. Chapter 446: Manufactured dwellings and structures, parks; Tourist facilities; Ownership records; Dealers and dealerships - 2011 Edition. Available at http://www.leg.state.or.us/ors/446.html (last accessed 12 March 2013).

OSS (Oregon Secretary of State). 2012. Oregon Administrative Rule: Department of consumer and business services. Salem, OR: State of Oregon. Available at http://arcweb.sos.state.or.us/pages/rules/oars_900/oar_918/918_650.html (last accessed 17 March 2013).

Pacione, M. 2009. Urban geography: A global perspective. London: Routledge.

PBP (Portland Bureau of Planning). 2013. Portland zoning code: Chapter 33.445:

Historic resource protection overlay zone. Available at http://www.portlandoregon.gov/bps/article/53352 (last accessed 13 March 2013).

Peck, J. and A. Tickell. 2002. Neoliberalizing space. Antipode 34(3): 380-404.

Purcell, M. 2013a. The Down-Deep Delight of Democracy. West Sussex, UK: WileyBlackwell.

--- 2013b. The right to the city: The struggle for democracy in the urban public realm. Policy \& Politics 41(3): 311-327.

--- 2008. Recapturing democracy: Neoliberalization and the struggle for alternative urban futures. New York: Routledge.

Revkin, A. 2008. Portland Again Tops a Sustainable Cities List. New York Times, 22 September. Available at http://dotearth.blogs.nytimes.com/2008/09/22/portlandagain-tops-a-sustainable-cities-

list $/$ module $=$ Search $\&$ mabReward $=$ relbias $\% 3 \mathrm{As} \% 2 \mathrm{C}\{\% 221 \% 22 \% 3 \mathrm{~A} \% 22 \mathrm{RI} \% 3$ A5\%22\} (last accessed 31 October 2014).

Roy, A. 2003. Paradigms of propertied citizenship: Transnational techniques of analysis. Urban Affairs Review 38(4): 463-491.

Sassen, S. 2002. Global cities and survival circuits. In Global woman, ed. Ehrenrich, B. and A. Hochschild, 254-274. New York: Henry Holt.

--- 2000. Territory and Territoriality in the Global Economy. International Sociology 15(2): 372-93.

Schmidt, B. 2013. Portland City Council will delay decision of Right 2 Dream Too homeless camp. The Oregonian, 15 October. Available at 
http://www.oregonlive.com/portland/index.ssf/2013/10/portland_city_council_wil 1_del.html (last accessed 9 December 2014).

Smith, N. 1996. The new urban frontier: Gentrification and the revanchist city. London: Routledge.

Smock, K. 2013. Point-in-time count of homelessness in Portland/Multnomah County, Oregon. Available at https://www.portlandoregon.gov/phb/article/451470 (last accessed 4 September 2014).

Soja, E. 2010. Seeking Spatial Justice. Minneapolis: University of Minnesota Press

--- 1980. The socio-spatial dialectic. Annals of the Association of American Geographers 70(2): 207-225.

Sparks, T. 2010. Broke Not Broken: Rights, Privacy, and Homelessness in Seattle. Urban Geography 31(6): 842-862.

Swyngedouw, E. 2004. Globalisation or 'glocalisation'? Networks, territories and rescaling. Cambridge Review of International Affairs 17(1): 24-48.

Takahashi, L., J. McElroy, and S. Rowe. 2002. The sociospatial stigmatization of homeless women with children. Urban Geography 23(4): 301-322.

Theen, A.2014. Old Town Chinatown: Portland Development Commission approves $\$ 1.5$ million deal for Right 2 Dream Too site. Oregon Live, 25 June, 2014. Available at http://www.oregonlive.com/portland/index.ssf/2014/06/old_town_chinatown_port land_de.html (last accessed 10 October 2014).

--- 2014. Right 2 Dream Too: Portland City Council approves $\$ 846,000$ to help homeless community; Dan Saltzman walks out. Oregon Live, 19 February, 2014. Available at

http://www.oregonlive.com/portland/index.ssf/2014/02/right_2_dream_too_portla nd_cit_1.html (last accessed 10 October 2014).

U.S. Census Bureau. 2014. State and County Quick facts: Portland, Oregon. Available at http://quickfacts.census.gov/qfd/states/41/4159000.html (last accessed 25 October 2014).

U.S. Census Bureau. 2014. Housing Vacancy and Homeownership: Annual Statistics: 2013, Rental Vacancy Rates for 75 Largest Metropolitan Statistical Areas: 2005- 
Present. Available at http://www.census.gov/housing/hvs/data/ann13ind.html (last accessed 17 November 2014).

U.S. HUD ((United States Department of Housing and Urban Development). 2014. 2014 Annual homeless assessment report to congress. Available at https://www.hudexchange.info/resource/4074/2014-ahar-part-1-pit-estimates-ofhomelessness/ (last accessed 30 October 2014).

U.S. HUD (United States Department of Housing and Urban Development). 2012. 2011 Annual homeless assessment report to congress. Available at https://www.onecpd.info/resources/documents/2011AHAR_FinalReport.pdf (last accessed 10 September 2014).

U.S. Ways and Means Committee. n.d. Federal housing assistance. Available at http://waysandmeans.house.gov/media/pdf/110/hap.pdf (last accessed 9 December 2014).

Vanderhart, D. 2014. District Attorney's Office, Police Mistakenly Targeted Sidewalk Use in Controversial COPP Program. Portland Mercury, 27 February. Available at

http://blogtown.portlandmercury.com/BlogtownPDX/archives/2014/02/27/breakin g-district-attorneys-office-police-mistakenly-targeted-sidewalk-use-incontroversial-copp-program (last accessed March 5, 2014).

Von Mahs, J. 2011. Introduction- An Americanization of Homelessness in Post-Industrial Countries. Urban Geography 32(7): 923-932.

--- 2005. The Sociospatial Exclusion of Single Homeless People in Berlin and Los Angeles. American Behavioral Scientist 48(8): 928-960.

--- 2001. Globalization, Welfare State Restructuring, and Urban Homelessness in Germany and the United States. Urban Geography 22(2): 457-81.

Weinstock, B. 2014. Affordable Rental Housing Crisis Hasn't Budged in Recovery. Street Roots. 28 February. Available at http://news.streetroots.org/2014/03/07/affordable-rental-housing-crisis-hasn-tbudged-recovery-call-redouble-our-efforts (last accessed March 12, 2014).

Wolch, J. and M. Dear. 1993. Malign Neglect. San Francisco: Jossey-Bass Publishers.

WRAP 2010. Update. Without Housing: Decades of Federal Housing Cutbacks, Massive Homelessness and Policy Failures. Western Regional Advocacy Project. 
---- 2006. Without Housing: Decades of Federal Housing Cutbacks, Massive Homelessness and Policy Failures. Western Regional Advocacy Project. 
Appendix A- Notes on my field work experiences

I would like to acknowledge that the process of my data collection, mostly the interviews I had with individuals using R2DT, was not a straightforward process. There were many days in which I went to R2DT to get interviews and left without anyone agreeing to speak with me. Of the thirty-odd days over the summer of 2013 I went to R2DT, there were at least eight to ten days I did not record an interview. Sometimes this was because I had nothing to offer people, like cash for food. I feel that many people were also not interested in speaking with me because they did not know me. Some staying at R2DT were conscious about speaking with reporters and may have assumed that was my role. For many reasons, then, getting interviews with people was not as simple as just showing up.

As an outsider to this group, it was important to me to have approval from the members of the rest site to interview people using R2DT. To gain access to this community, I went to a weekly community meeting to describe to the members what I was trying to do with my research and get to get feedback from them on how this would work best. I explained that I was interested in speaking with anyone staying at R2DT about their experiences at the rest site. It was important and valuable for me do this as I was able to familiarize myself with many of the people who were staying at the site. Subsequent visits to the site then were unscheduled, as I could come back to the site at random and be greeted by the members who now recognized me. This was incredibly helpful in terms of getting people to agree to speak with me. But after I finished interviewing the more permanent members who wanted to be interviewed, I had only ten interviews.

I realized that the members constituted a small majority of people staying at the rest site. And I wanted to get a wider sample of experiences. I realized that I needed to speak with overnight sleepers. This became quite the task. Overnight sleepers are generally not around the rest site during the daytime. If they were around during the day, they were sleeping. If they were signing out of the site, they were off to go find a meal somewhere; also not a great time to ask sometime for an interview. I never wanted to bother anyone during the process, so I was content with people saying no and ending conversations with that. With that said, getting a larger sample of overnighter perspectives was a very time-consuming process.

Eventually I started waiting in line with overnight sleepers who were signing in for the night. This was one of the few times I could speak with new faces. I used my time waiting in line to start up conversations with people who intended on staying that night, but who had already stayed at the rest site before. After a bit of conversation, I would 
bring up the fact that I was here to speak with people about their experiences with homelessness and specifically with the rest site. While I still got some "no" responses, I found this to be the only method of finding overnighters to speak with. As time went on, and I continued to line up, people who I had already interviewed and were waiting in line would let other overnighters know that I was someone they could trust to speak with and that I had no "angle" with my questions. This was another way I created trust with this community.

I was fortunate to have a few individuals help me out during this process. One person in particular, Scotty (he asked me to use his name- but has since moved out of state), helped me enormously by setting up interviews. At least three or four days that I went to R2DT early on in my field work, Scotty would be around wondering how he could help. I asked him where I might find individuals staying, or who had stayed, at R2DT that I could speak with. Many times he took me to the park a few blocks away from the rest site to introduce me to people. This was generally during the middle of the day, when there were less resources being utilized around this neighborhood. Not only did he connect me with people to interview, he would go around lining up other interviews while I was speaking with people in the park. His effort and actions were incredibly selfless and I could not be more thankful for his help.

Finally, the entire reason this research got started was because of a fortuitous encounter with a R2DT board member. Very early on in my thinking about this project I was at tea shop and was overheard while talking about R2DT. She heard me asking about what I saw when I walked by the rest site for the first time. After a long conversation with her, I stayed in contact and she helped me initiate my presence at the site and also spoke with me for an interview. This research was facilitated by her help and I am very thankful to have met her.

My intention behind this project is first and foremost in consideration of those less fortunate, living on the street without consistent access to shelter. It is out of this concern that my research is fueled. As I got deeper into the project, the more meaningful it became, and the more I appreciated the many individuals I met who welcomed and shared their experience with me. It should be noted that many individuals who I spoke with at the onset of my field work have since found stable housing. Others have moved out of Portland and have hopefully found stability in their lives. 


\section{Appendix B - Interview Questions}

1. How old are you?

2. How long have you been without housing?

3. Have you been houseless anywhere else in Portland? If so, where? In what areas of the city did you stay?

4. How many residences have you stayed at in the past year?

5. How long have you been at Right 2 Dream Too?

6. Why have you chosen to stay at R2DT over other places?

7. How has your experience been while staying at R2DT?

8. Do you use any social services other than R2DT in downtown? How often? How do you get to these services?

9. Do you currently have prospects to obtain stable housing?

10. If R2DT were moved tomorrow, what is a good area for it to be located? Why? 
Appendix C- Code Percentages and Frequency

\begin{tabular}{|c|l|c|c|}
\hline \multicolumn{3}{|c|}{ Initial Code Book } \\
\hline Main Theme & \multicolumn{1}{|c|}{ Sub Theme } & Percentage & Frequency \\
\hline \multirow{4}{*}{ Centrality } & Proximity to Resources & $21 / 28=75 \%$ & 31 \\
\cline { 2 - 4 } & Mobility & $7 / 28=25 \%$ & 8 \\
\cline { 2 - 4 } & Visibility & $5 / 28=18 \%$ & 5 \\
\hline \multirow{4}{*}{$\begin{array}{c}\text { Supportive } \\
\text { Space }\end{array}$} & Protection/Safety & $14 / 28=50 \%$ & 17 \\
\cline { 2 - 4 } & Optionless & $12 / 28=43 \%$ & 13 \\
\cline { 2 - 4 } & Helpful as Resource & $12 / 28=43 \%$ & 13 \\
\cline { 2 - 4 } & Accommodating & $10 / 28=36 \%$ & 15 \\
\cline { 2 - 4 } & Health & $6 / 28=21 \%$ & 6 \\
\cline { 2 - 4 } & Stability & $6 / 28=21 \%$ & 4 \\
\cline { 2 - 4 } & Avoid Separation & $5 / 28=18 \%$ & 5 \\
\hline \multirow{3}{*}{ Interaction } & Communal Living/ Responsibility & $18 / 28=64 \%$ & 23 \\
\cline { 2 - 4 } & Spatial Constraints & $7 / 28=25 \%$ & 11 \\
\cline { 2 - 4 } & Organization & $7 / 28=25 \%$ & 9 \\
\cline { 2 - 4 } & Disrespect & $5 / 28=18 \%$ & 5 \\
\cline { 2 - 4 } & Privilege & $4 / 28=14 \%$ & 3 \\
\hline
\end{tabular}

This code book was generated in my second round of theme construction. Displayed in this table is the prominent themes discussed in the body of the research and their subthemes. The percentage column identifies how many unique mentions, or extracts from the data, that code was applied to. The frequency refers to the total number of mentions that code was applied to the data extracts. 
Appendix D- Human Subjects Review Approval 
Date: July 24,2013

To: $\quad$ Thomas Harvey / Stephen Przybylinski

From: Todd Bodner, HSRRC Chair

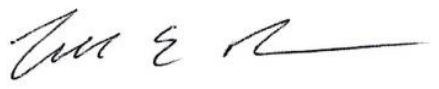

Re: HSRRC approval for your project titled, "Right to the City: A Portland, Oregon Case Study of Homelessness" (HSRRC Proposal \# 132706)

Approval-Expiration: July 24, 2013 - July 23, 2014

Review Type: $\quad$ Expedited, Categories 6,7

Dear Thomas and Stephen,

In accordance with your request, the Human Subjects Research Review Committee has reviewed your proposal referenced above for compliance with PSU and DHHS policies and regulations covering the protection of human subjects. The Committee is satisfied that your provisions for protecting the rights and welfare of all subjects participating in the research are adequate, and your project is approved. Please note the following requirements:

Training: All investigators involved with this protocol must complete either the CITI or NIH human subjects training courses as soon as possible.

Approval: You are approved to conduct this research study only during the period of approval cited above; and the research must be conducted according to the plans and protocol submitted (approved copy enclosed).

Consent: Signed consent is required from all participants in this study.

Changes to Protocol: Any changes in the proposed study, whether to procedures, survey instruments, consent forms or cover letters, must be outlined and submitted to the Committee immediately. The proposed changes cannot be implemented before they have been reviewed and approved by the Committee.

Continuing Review: This approval will expire on $07 / 23 / 2014$. It is the investigator's responsibility to ensure that a Continuing Review Report on the status of the project is submitted to the HSRRC two months before the expiration date, and that approval of the study is kept current. The Continuing Review Report is available at www.rsp.pdx.edu/compliance human.php and in the Office of Research and Strategic Partnerships (RSP).

Adverse Reactions and/or Unanticipated Problems: If any adverse reactions or unanticipated problems occur as a result of this study, you are required to notify the Committee immediately. If the issue is serious, approval may be withdrawn pending an investigation by the Committee.

Completion of Study: Please notify the Committee as soon as your research has been completed. Study records, including protocols and signed consent forms for each participant, must be kept by the investigator in a secure location for three years following completion of the study (or per any requirements specified by the project's funding agency).

If you have questions or concerns, please contact the Office of Research Integrity in the PSU RSP at 503-725-2227, Market Center Building, Suite 620 . 